\title{
Factors associated with brain ageing - a systematic review
}

Jo Wrigglesworth ${ }^{1}$, Phillip Ward ${ }^{2,3,4}$, lan H. Harding ${ }^{2,5}$, Dinuli Nilaweera', Zimu Wu' ${ }^{1}$, Robyn L. Woods and Joanne Ryan ${ }^{1 *}$ (D)

\begin{abstract}
Background: Brain age is a biomarker that predicts chronological age using neuroimaging features. Deviations of this predicted age from chronological age is considered a sign of age-related brain changes, or commonly referred to as brain ageing. The aim of this systematic review is to identify and synthesize the evidence for an association between lifestyle, health factors and diseases in adult populations, with brain ageing.
\end{abstract}

Methods: This systematic review was undertaken in accordance with the PRISMA guidelines. A systematic search of Embase and Medline was conducted to identify relevant articles using search terms relating to the prediction of age from neuroimaging data or brain ageing. The tables of two recent review papers on brain ageing were also examined to identify additional articles. Studies were limited to adult humans (aged 18 years and above), from clinical or general populations. Exposures and study design of all types were also considered eligible.

Results: A systematic search identified 52 studies, which examined brain ageing in clinical and community dwelling adults (mean age between 21 to 78 years, $~ 37 \%$ were female). Most research came from studies of individuals diagnosed with schizophrenia or Alzheimer's disease, or healthy populations that were assessed cognitively. From these studies, psychiatric and neurologic diseases were most commonly associated with accelerated brain ageing, though not all studies drew the same conclusions. Evidence for all other exposures is nascent, and relatively inconsistent. Heterogenous methodologies, or methods of outcome ascertainment, were partly accountable.

Conclusion: This systematic review summarised the current evidence for an association between genetic, lifestyle, health, or diseases and brain ageing. Overall there is good evidence to suggest schizophrenia and Alzheimer's disease are associated with accelerated brain ageing. Evidence for all other exposures was mixed or limited. This was mostly due to a lack of independent replication, and inconsistency across studies that were primarily cross sectional in nature. Future research efforts should focus on replicating current findings, using prospective datasets.

Trial registration: A copy of the review protocol can be accessed through PROSPERO, registration number CRD42020142817.

Keywords: Brain ageing, BrainAGE, Predicted age difference, Age prediction, Neuroimaging, Machine learning, Biomarker, Age-related brain changes

\footnotetext{
* Correspondence: joanne.ryan@monash.edu

${ }^{1}$ School of Public Health and Preventive Medicine, Monash University, Melbourne, Victoria 3004, Australia

Full list of author information is available at the end of the article
}

(c) The Author(s). 2021 Open Access This article is licensed under a Creative Commons Attribution 4.0 International License, which permits use, sharing, adaptation, distribution and reproduction in any medium or format, as long as you give appropriate credit to the original author(s) and the source, provide a link to the Creative Commons licence, and indicate if changes were made. The images or other third party material in this article are included in the article's Creative Commons licence, unless indicated otherwise in a credit line to the material. If material is not included in the article's Creative Commons licence and your intended use is not permitted by statutory regulation or exceeds the permitted use, you will need to obtain permission directly from the copyright holder. To view a copy of this licence, visit http://creativecommons.org/licenses/by/4.0/. The Creative Commons Public Domain Dedication waiver (http://creativecommons.org/publicdomain/zero/1.0/) applies to the data made available in this article, unless otherwise stated in a credit line to the data. 


\section{Introduction}

Ageing is a complex biological process characterised by an accumulation of molecular and cellular damages over the lifespan [1-3]. The body's inability to repair this damage leads to a subsequent loss of physiological functions [1]. These include sensory, motor, and cognitive functions that, when impaired, impact quality of life [4]. Age is also a major risk factor for many life threatening diseases including cancer, cardiovascular disease, and neurodegenerative disorders [1]. The trajectory of ageing, however, varies within the population, and thus, chronological age is not always a reliable predictor of age-related risk. Genetic and environmental factors are diverse among the population, and have varied effects on ageing processes occurring within individual cells, and tissue types [2].

The brain is particularly sensitive to the effects of ageing, manifesting as changes in structure and cognitive function [5-8]. Neuroimaging technologies, including magnetic resonance imaging (MRI), have made it possible to monitor these changes in vivo. The most common changes associated with ageing are brain atrophy (i.e., loss of grey matter volume and cortical thinning) [9-12], a reduction in white matter integrity and volume, and abnormal functional connectivity [7, 13-16]. When severe, these phenotypes can be considered a sign of accelerated ageing or an underlying disease process $[5,6]$. Though neuroimaging research has advanced our understanding of these processes, current group based analyses (i.e., mass univariate modelling that uses chronological age to predict neuroimaging features), cannot account for the diversity of individual ageing trajectories [17].

Among these developments are efforts focused on identifying individual biomarkers of age-related brain changes [18]. So-called 'brain age' algorithms use neuroimaging features to capture the changes in the brain that commonly occur with age [18]. Typically, this requires training a multivariate statistical model to learn normative patterns of brain ageing, before being applied to predict individual brain ages in a group of interest. The difference between predicted biological and actual chronological age signifies a deviation from the normal ageing trajectory, and has the potential to identify individuals with disease, monitor treatment effects, or identify lifestyle factors that are beneficial or detrimental to brain health [18-20].

A recent literature review summarised different methods that use brain volume to define brain age [20]; whilst another provided a more comprehensive overview of all methodologies currently being applied in the field, including developmental and animal studies [21]. However, to date, no systematic review has summarised agerelated brain changes (referred to as 'brain ageing'), defined solely by the deviation of estimated brain age from chronological age, in human adult populations. Thus, the aim of this systematic review is to identify and synthesize the evidence for an association between lifestyle, health factors, and diseases in adult populations, with brain ageing.

\section{Methods}

\section{Protocol and registration}

This systematic review was undertaken in accordance with the PRISMA guidelines (http://www.prismastatement.org) - the 2009 checklist is provided in Additional File 1 [22]. In compliance with these guidelines, a record of this protocol can be accessed through PROSPERO via the following registration number CRD42020142817.

\section{Eligibility criteria}

This systematic review included studies investigating brain ageing in adult humans (mean age 18 years and above), from community or clinical populations. Studies measured exposures of all types, including genetic, health, and lifestyle factors, and the outcome was brain ageing. All study designs (cohort and case-control) were eligible, with brain ageing measured either at the same time as the exposure (cross sectionally) or a later timepoint (longitudinally). Papers limited to evaluating the sensitivity of different methodologies (e.g. sample size) on brain ageing were not included.

\section{Brain ageing}

Estimates of brain age were considered eligible when chronological age was predicted from neuroimaging features, acquired from any imaging modality (e.g., MRI). Eligible studies were those which examined brain ageing as the difference between brain age and chronological age. Studies using alternative methods for calculating brain ageing, including the slope between chronological age and brain age [23]; or the group differences in models of brain features as a function of age [24], were excluded.

\section{Information sources and search strategy}

A systematic search of Embase via Ovid (1974 to present) and Ovid MEDLINE was conducted to identify relevant articles, using search terms relating to the prediction of age from neuroimaging data or brain ageing: (BrainAge.mp. OR Neuroanatomical adj3 age.mp. OR brain age.mp. OR age adj3 estimat".mp. AND Imaging.mp) OR (BrainAge.mp. OR Neuroanatomical adj3 ag*.mp. OR age adj3 estimat".mp OR brain ag*.mp. OR BrainAGE adj3 accelerat*.mp OR brain age gap.mp OR BrainPAD.mp OR Brain adj1 predict*.mp AND imaging.mp. AND chronological age.mp. AND accelerat* 
adj3 ag*.mp). No yearly limit was set, however searches were limited to studies only including human participants, and articles published in English. The tables of two recent review papers on brain ageing $[20,21]$ were also examined to identify additional articles.

\section{Study selection}

Following the initial search, duplicate articles were removed by one reviewer (JW). Article abstracts and titles were screened independently by three reviewers (JW, $\mathrm{DN}, \mathrm{ZW})$, followed by a full text review of the eligible texts. In the case of discordance, a fourth reviewer (JR) was involved to provide a final verdict.

\section{Data extraction}

For each included study, the following information was extracted onto a standardised data extraction form: Study characteristics (i.e., name, country and design); Participant characteristics (i.e., sample size, mean age and/or range, number of female participants); neuroimaging features used for brain age prediction (i.e., modality, protocol, and features) and statistical methodologies (i.e., algorithm, and cross validation, and adjustment for age bias); and exposures (e.g., cognitive function, disease type). Main findings and details of any adjustments for confounders were also extracted.

\section{Data synthesis/summary measures}

A narrative synthesis of the main brain ageing findings is provided, and grouped according to the type of exposure. Findings are summarised quantitatively in tables with effect sizes (when available), regardless of statistical significance. Effect sizes of all types are reported, and include correlations; differences in mean brain ageing (including Cohens D/Eta squared); 95\% confidence intervals (when $p$-value was not available), and beta values (both un/standardized) from regression models. Authors considered brain ageing methodologies, and/or participant characteristics too heterogenous to conduct a meta-analysis.

\section{Risk of bias}

Included articles were assessed for risk of bias using a modified version of the Joanna Briggs Institute Critical Appraisal Checklist for Randomized Control Trial, CaseStudy or Cohort study, as appropriate [25]. This assessment was merely a tool for determining the quality of information extracted from each article, rather than a means for excluding papers. This was completed by three reviewers (JW, ZW, DN), independently. Any discrepancies were discussed and resolved through consensus.

\section{Results}

\section{Study selection}

An initial search of Medline and Embase resulted in 2514 articles, and an additional three papers were identified from prior reviews on brain ageing (Fig. 1) [20, 21]. After removing duplicates, the titles and abstracts of 1896 articles were screened, and 1637 papers excluded. Two hundred and fifty-nine papers underwent a full text review. From these papers, a further 207 articles were removed as they did not meet the eligibility criteria (ineligible article type; sample of children/adolescents only; or ineligible calculation of age prediction). A total of $52 \mathrm{pa}$ pers were thus included in this systematic review.

\section{Participant characteristics}

Studies investigated brain ageing in samples ranging in size (between 5 to 31,227 participants), and age (mean age between 21 to 78 years). One study compared one male with Prader-Willi syndrome to a small sample of 95 healthy controls (approximately 39\% were male) [26]. Four studies included children, and/or adolescents as well as adults, but fit the inclusion criteria given that the mean age of the sample was 18 years or older [27-30]. All but two studies included both men and women, with the percentage of women ranging from 4.4 to $89.1 \%$. Five of these studies, however, did not report the number of men or women [30-34]. Of the two remaining studies, one involved military serving male twins [35], and a second focused on brain ageing in postmenopausal women [36].

Twenty-nine studies sub-sampled participants from a larger cohort study, nine were case-controls $[26,30,37-$ 43]. Of the remaining 10 case-control studies, eight had sampled participants from registries, hospitals (i.e., both in and outpatient services) or treatment clinics, university research institutes, or the local community $[29,44-$ 50], while two were unclear [51, 52]. The Early Stages of Schizophrenia study [38, 41], the UK Biobank [19, 32, 53, 54] and the Alzheimer's Disease Neuroimaging Initiative (ADNI) [33, 55-58] were cohorts sampled on more than one occasion. Thirteen studies included prospective data [28, 30, 31, 33, 35, 36, 47, 56, 58-62].

One study estimated brain age for participants who were a part of a randomised control trial [63]. Six studies pooled data from multiple studies $[26,30,60,64-66]$; while three studies involved more than one type of study design [30, 41, 47].

\section{Summary of brain ageing findings}

Brain ageing was investigated in relation to a number of exposures. These are summarised in the following text and tables, and are grouped according to the type of exposure. 'Accelerated' and 'decelerated' are terms commonly used to describe the direction of brain ageing 


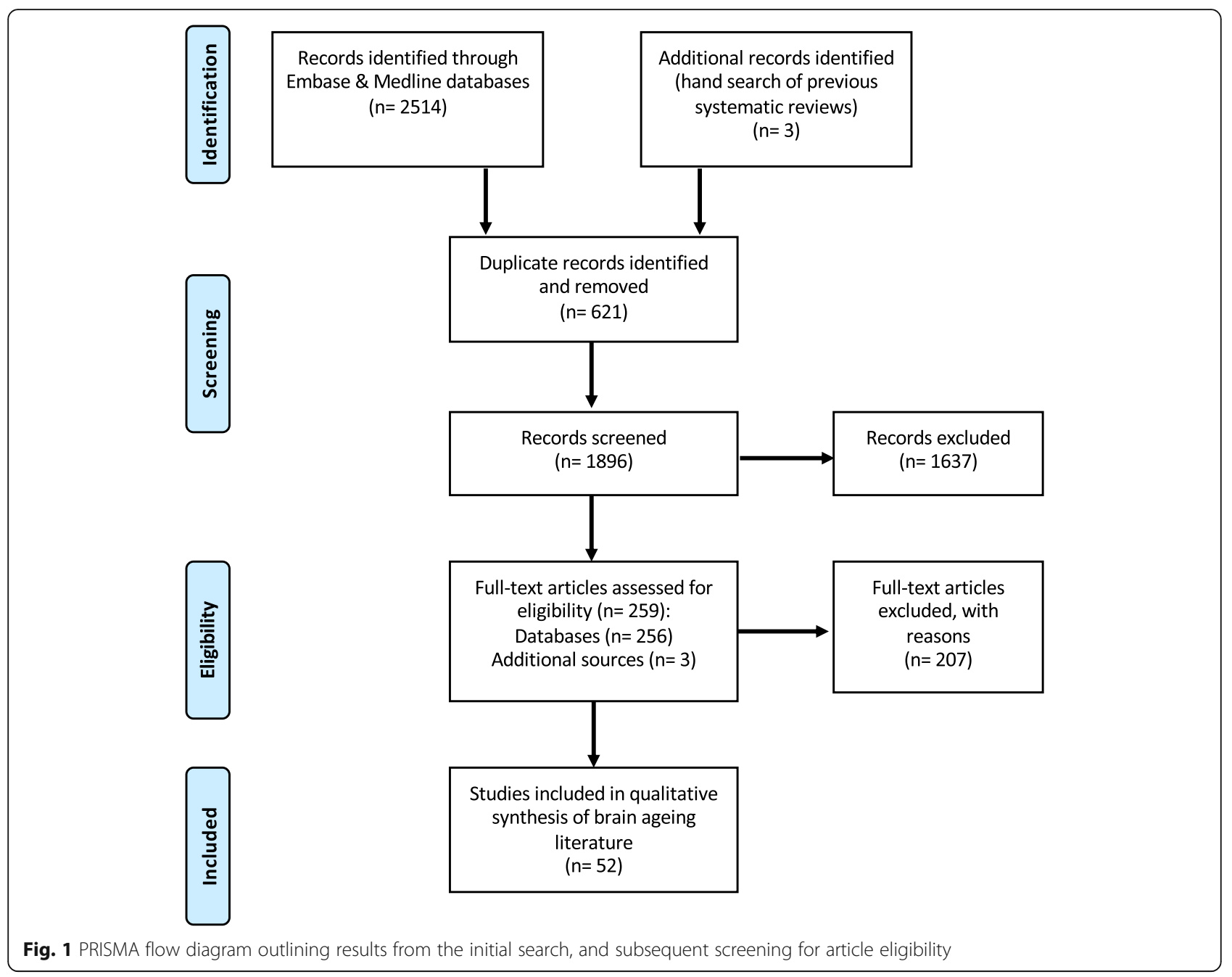

(i.e., accelerated defines greater age-related changes to the brain; while decelerated suggests fewer changes) and thus will be used in the subsequent text. Similarly, in longitudinal studies, the 'rate' is conventionally used to define a change in brain age, but can be calculated by either regressing time on brain age, or dividing change in brain age by the time interval between the imaging acquisitions. Thus, while rate will be used throughout the following text, methods will be defined in tables accordingly.

In tables, brain ageing (i.e., brain age - chronological age) was abbreviated as the "brain age gap (GAP)", and used to summarise results. Though conceptually the same, two studies subtracted brain age from chronological age, and thus, "CA-BA" is used to report these results $[27,64]$. When studies involve a common brain age framework (i.e., was referenced by more than one study), terms specific to this framework will be used. These include the "Brain age gap estimate (BrainAGE) score" [55], "Predicted age difference (PAD) score" [51], and
"Brain ageing (BA) score" [67], and are specific to these referenced authors.

\section{Psychiatric disorders}

Thirteen studies investigated brain ageing in psychiatric disorders [27, 30, 32, 34, 37, 38, 41, 44, 49, 50, 60, 66], eight focused on schizophrenia (SZ) [27, 30, 32, 34, 38, 41, 49, 66] (Table 1). All studies report accelerated brain ageing in SZ (ranging between 2.3 and 7.8 years), though the majority included samples less than 100 participants. Of these studies, six found accelerated brain ageing to be significantly different to healthy controls [32, 34, 38, $41,49,66]$; while two made no statistical comparison between groups $[27,30]$. Five studies also included patients with bipolar disorder. Four of these found brain ageing to be comparable to healthy controls [32, 34, 41, 49]. The fifth study only reported accelerated brain ageing, and made no statistical comparison to a control group [27]. 


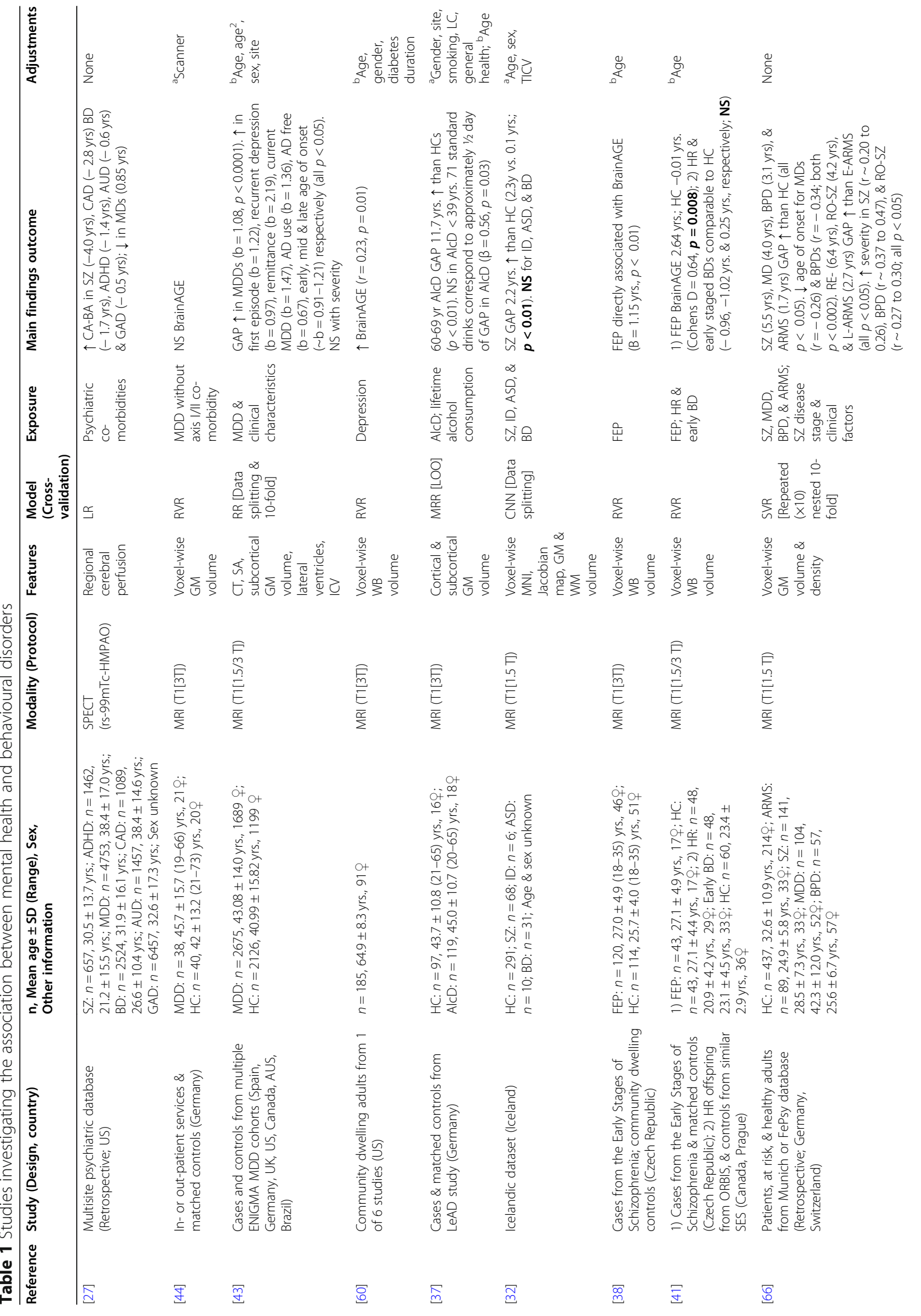




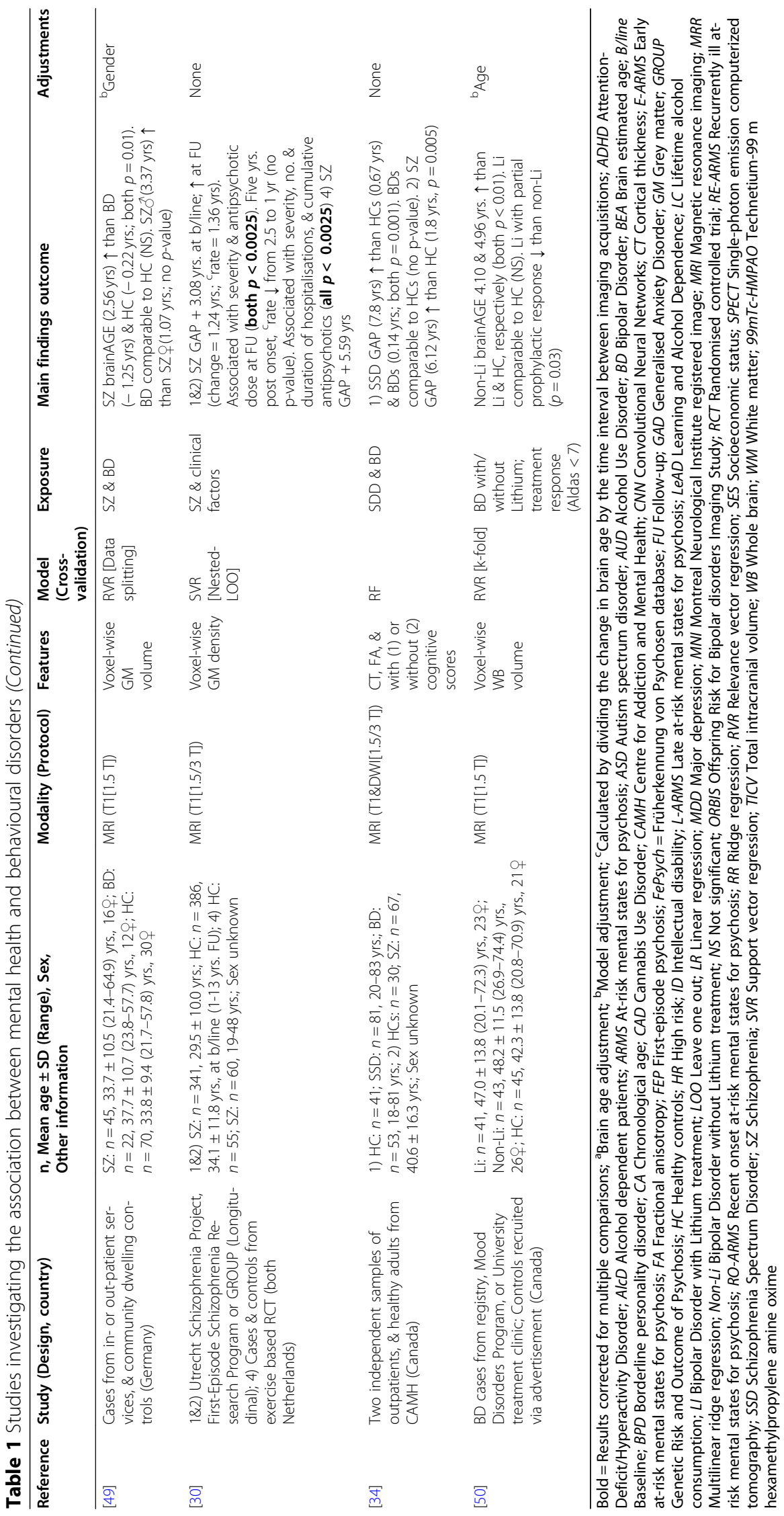


Fewer studies investigated other psychiatric disorders. There were four studies involving patients with major depression (MD), but with mixed findings. Specifically, two found accelerated brain ageing in MDs, that was significantly different to controls $[43,66]$; a second study, involving fewer cases, found no difference between MDs and controls [44], and a third reported decelerated brain ageing but made no statistical comparison to a control group [27]. A fifth study analysed associations in a relatively large sample of community dwelling middle-aged adults, and reported a positive correlation between depression scores and brain ageing [60].

\section{Neurological disease}

A total of 18 studies investigated brain ageing in relation to neurological diseases, the most common being mild cognitive impairment (MCI), Alzheimer's Disease (AD) and epilepsy (Table 2). Four of the five studies included a small group of AD participants (ranging between 27 to 76 in size), and reported a significantly higher accelerated brain ageing (ranging between 5.36 and 10 years, at baseline) relative to healthy controls - three sampled participants from the ADNI $[33,55,56]$. The fifth study observed decelerated brain ageing, but using a larger sample of participants with dementia (including AD), and did not statistically compare these findings to a healthy control group [27]. Two studies also included prospective data from the ADNI study, and reported a significantly higher accelerated brain ageing at followup, and a greater rate of brain ageing in ADs, relative to healthy controls or participants with stable MCI $[33,56]$. All measures of brain ageing (baseline, follow-up and the rate) were significantly higher when participants progressed from $\mathrm{MCI}$ to $\mathrm{AD}$, relative to stable $\mathrm{MCI}$ and healthy controls $[33,56]$. An additional study that also sampled participants from the ADNI study reported a significantly higher accelerated brain ageing (i.e., measured at baseline only) in participants progressing from MCIs onto $\mathrm{AD}$ sooner than later, relative to individuals with a stable $\mathrm{MCI}$, or had progressed onto $\mathrm{AD}$ at a later stage [58].

Beyond looking specifically at diagnostic categories of dementia, four studies also correlated brain ageing with cognitive scores. These studies used similar cognitive measures (Mini-Mental State Examination (MMSE) [78, 79], Clinical Dementia Rating (CDR)/CDR-sub of boxes [75] or Alzheimer's Disease Assessment Scale (ADAS) [72-74]) but reported mixed results [33, 56, 58, 68]. Of the three studies including participants from the ADNI, one observed a significant correlation between brain ageing and each of the CDR, ADAS, and MMSE at both baseline and follow up, when pooling healthy controls with diagnostic groups [33]. A second study only included those with MCI, and observed a correlation with
CDR and ADAS at baseline that increased at each follow up; correlations with MMSE were observed only at follow up [58]. A third study reported the strongest correlations in individuals with $\mathrm{AD}$ was between brain ageing and MMSE, and in progressive MCI with ADAS [56]. When pooling healthy controls with diagnostic groups, an alternative fourth study also observed a correlation with the CDR, ADAS, MMSE, [68].

Four studies investigated brain ageing in relation to various types of epilepsy [40, 45, 52, 69]. Specifically, two studies focused on small groups (ranging between 17 to 104) of participants with temporal lobe epilepsy, and report accelerated brain ageing [45, 69]. However, one was a case-control study that observed a significant difference to healthy controls, but only when seizures were localised to the right hemisphere [45], while the second, slightly larger cohort study had not statistically compared these findings to healthy controls [69]. The two-remaining case-control studies investigated brain ageing in patients with other forms of epilepsy. One compared brain ageing in medical refractory epilepsy (MRE) ( 50\% of the patients experienced seizures in the temporal lobe) to newly diagnosed focal epilepsy (NDE), and reported significant accelerated brain ageing in MREs only, as NDEs were comparable to healthy controls [40]. The second reported accelerated brain ageing in all participants with epilepsy (i.e., focal and generalised), including neuropsychiatric conditions with episodes that resemble epileptic seizures (i.e., psychogenic nonepileptic seizures), except those with extra-temporal lobe focal epilepsy, had a significantly higher accelerated brain ageing than healthy controls $[52,80]$.

Fewer studies analysed the effects of stroke [59, 71], traumatic brain injury (TBI) [27, 51, 70], multiple sclerosis (MS) [28, 47], or Parkinson's disease on brain ageing [48]. Three studies analysed brain ageing in TBI patients, but report mixed results. Specifically, two smaller sample studies found significantly higher accelerated brain ageing in TBI patients relative to healthy controls [51, 70]; a third reported decelerated brain ageing for a large cohort of TBI patients, but did not statistically compare findings to other diagnostic groups [27]. The two former studies also investigated time since TBI, but only one found a significant positive correlation with the time since TBI $[51,70]$.

Of the remaining studies, two reported greater crosssectional estimates of accelerated brain ageing for patients with MS relative to healthy controls $[28,47]$. Longitudinal assessments by one of these two studies resulted in a higher annual rate of accelerated brain ageing in a large pooled sample of MS and clinically isolated syndrome patients (i.e., individuals with a greater likelihood of MS), relative to healthy controls [28, 81]; the second did not compare findings to healthy controls, but 


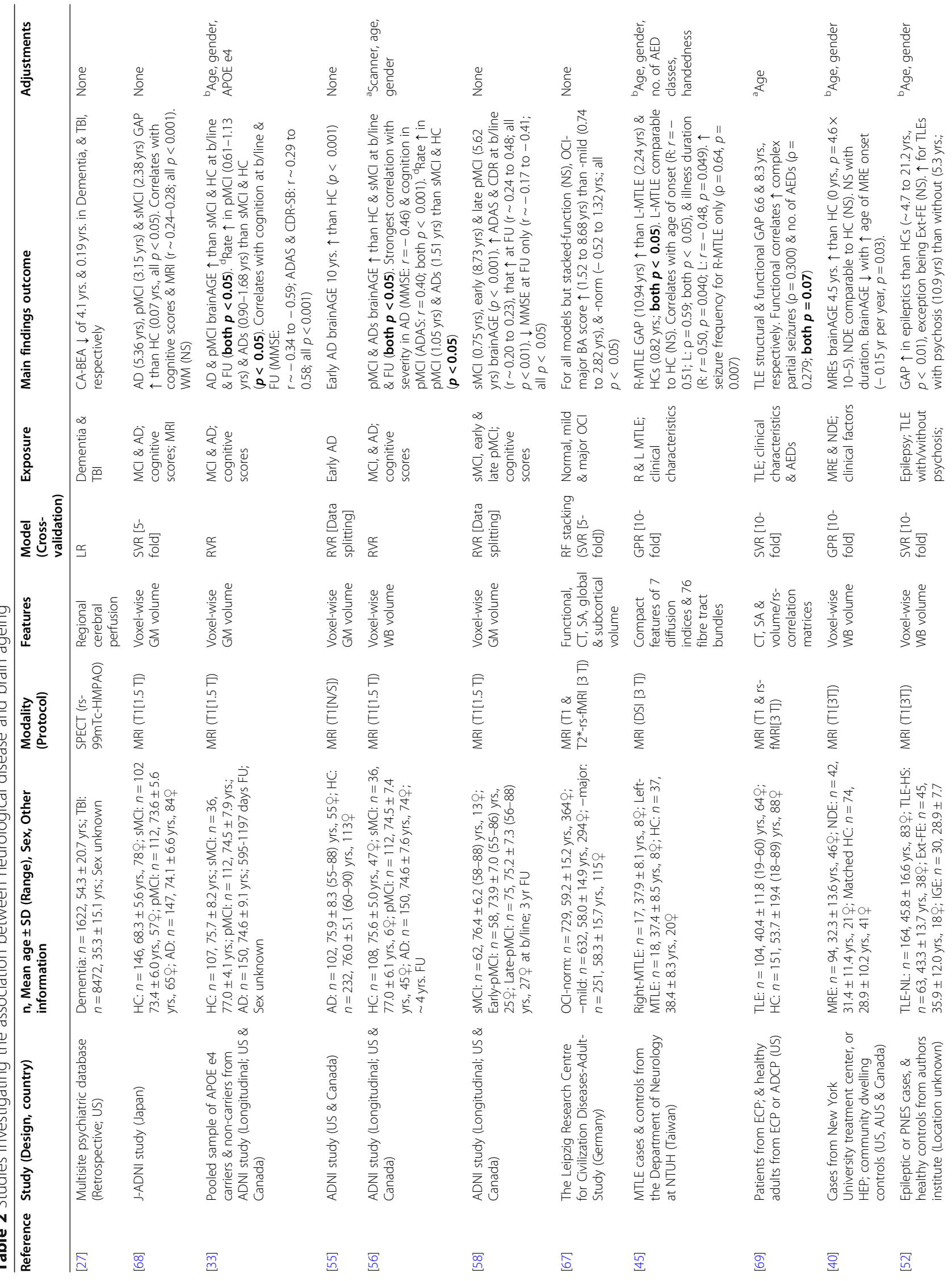




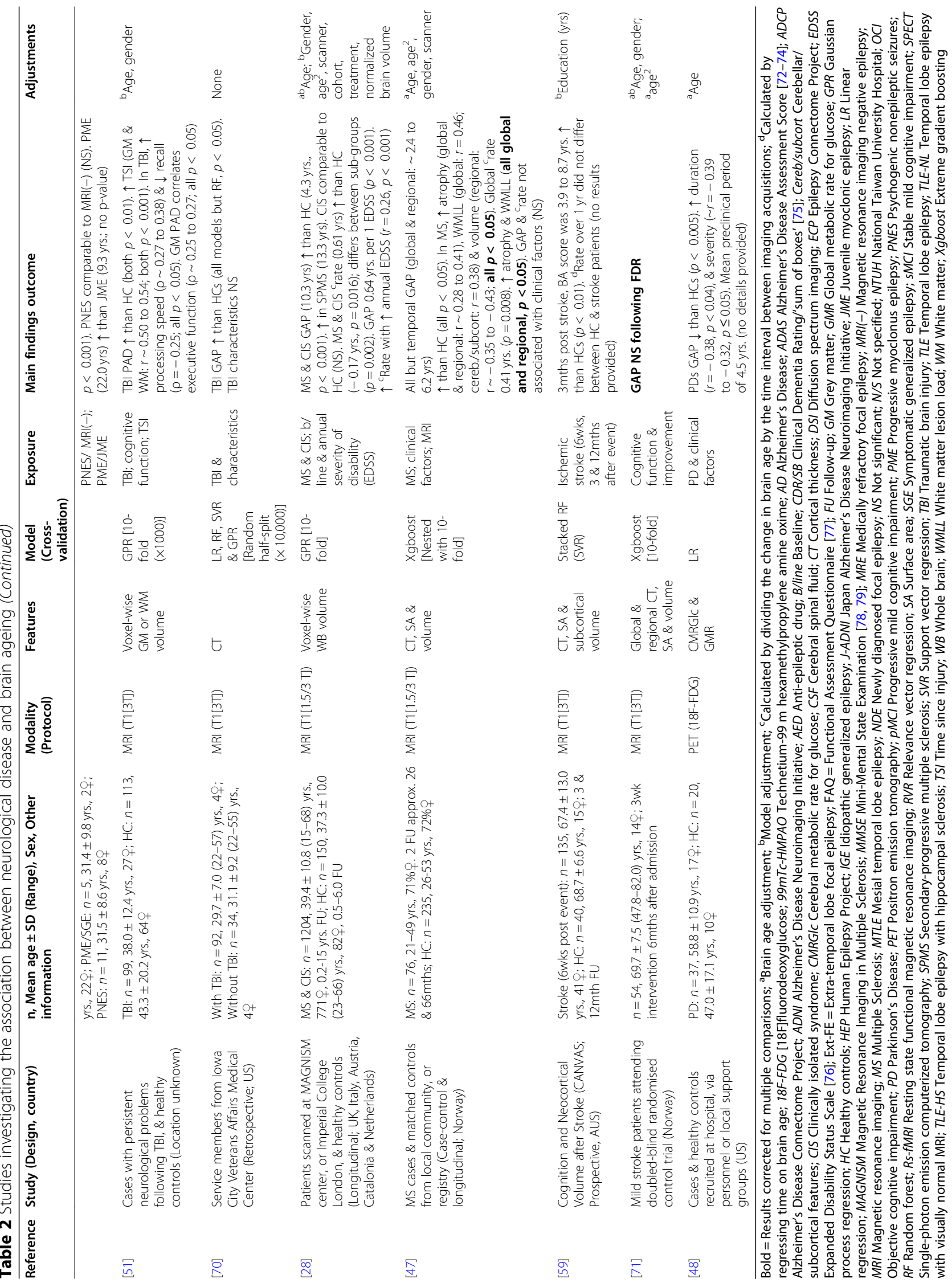


also observed an annual accelerated rate of brain ageing when using a much smaller sample of MS patients [47]. In stroke patients, one randomised control study found no correlation between regional or global estimates of brain ageing with cognitive function [71], while a second prospective cohort study found a significantly higher brain ageing than healthy controls, despite features used to estimate brain age [59]. For the latter study, however, the direction of brain ageing (i.e., accelerated/decelerated) varied between models, for both patients and controls [59]. From this study, the rate of brain ageing was also comparable between patients and healthy controls, though no statistics were reported [59].

\section{Health, physical and biological markers}

Fourteen studies investigated brain ageing in relation to diseases without a primary neurological presentation (Human Immunodeficiency Virus (HIV) and type II diabetes), markers of health (e.g., biological and physical), hormones, medications, chronic pain, or mortality risk (Table 3) [19, 36, 38, 39, 53, 54, 57, 60-63, 66, 82, 83]. Most commonly reported were associations with body mass index (BMI) [38, 53, 57, 66]. Of the four studies investigating $\mathrm{BMI}$, two involved community dwelling, initially healthy older adults from the ADNI cohort study or the UK Biobank, while the other two studies sampled young adult patients with SZ [38, 53, 57, 66]. The two former studies both reported a positive correlation with BMI, however, the larger cohort study observed this association when predicting age for both genders, or females only [53]; while the second, smaller sample study reported this effect in males only when defined ageing for the total sample $[53,57]$. A significant positive association with BMI was also reported in SZ patients. However, one study found this effect to be independent to an $\mathrm{SZ}$ diagnosis (i.e., main effects of BMI and SZ on brain ageing were evident, but no significant BMI-by-SZ interaction); while the second only observed an association for a smaller group of patients with a recent onset of SZ [38].

Three small cohort studies ( $\leq 162$ participants) analysed the effects of HIV [39, 62, 82]. Regardless of model and feature type, all studies reported accelerated brain ageing in HIV positive patients (ranging between 1.17 and 5.87 years). For two studies, this brain ageing was significantly higher than HIV-negative controls [39, 82]; while a third study's findings were relative only to the model (i.e., a null hypothesis that predicted minus chronological age equals zero) [62]. Associations between brain ageing and HIV clinical characteristics (e.g., years since diagnosis, cell counts (CD4)) were also investigated. One study reported an association between higher brain ageing and prior Acquired ImmunoDeficiency Syndrome status [62] whilst another with viral loading [39]. In contrast, a third observed no significant association with any of the clinical or health factors (all $p>0.10)$ [82].

Two studies considered the influence of female sex hormones, however, one in the context of pregnancy, while the other during a normal menstrual cycle [36, $61]$. Both studies relied on small sample sizes of young adult women ( $\leq 14$ participants). Neither study found significant correlations between brain ageing and progesterone $[36,61]$ but one reported a significant negative correlation with estradiol (i.e., measured at time point two, when it was most elevated) [61].

\section{Environmental and lifestyle factors}

Seven eligible studies investigated environmental influences on brain ageing with the most common being smoking and alcohol consumption (Table 4) [53, $54,60]$. Two of the three studies involved a large sample of participants from the UK Biobank, and report a positive association between brain ageing (estimated using different algorithms) and alcohol intake, however, the second also observed a correlation when estimating brain age for females only [53, 54]. Both studies also reported a significant positive correlation with smoking [53, 54]. A third independent study also reported a significant, positive association with smoking, and alcohol, but for fewer community dwelling adults [60]. Meditation practitioners, and amateur/ professional musicians were reported to have a significantly lower brain ageing than controls, but were each analysed by one study [29, 42]. Similarly, one study found a higher education, or a greater flight of stairs climbed, to be significantly associated with decelerated brain ageing [64].

\section{Genetic influences}

Five studies investigated genetic influences on brain ageing (Table 5). Two studies reported no significant difference in brain ageing due to Apolipoprotein E (APOE) e4 carrier status in older adults [33, 84]. One, however, used prospective data from the ADNI study, and found a significantly higher rate of accelerated ageing in APOE e4 carriers [33]. Both study samples, however, involved a limited number of participants ( $\leq 101$ participants), and thus may be under-powered.

One genome wide association study using data from the UK Biobank, found and replicated a significant association between brain ageing and two genetic variants one spanning many genes, including $M A P T$, which encodes for the tau protein (i.e., considered to play a prominent role in Frontotemporal dementia, and other neurodegenerative disorders) $[85,86]$; the second is near the TREK-1 gene, that has been reported (in mice) to play a role in memory impairment, cerebral ischemia, and blood brain barrier dysfunction [87-89]. 


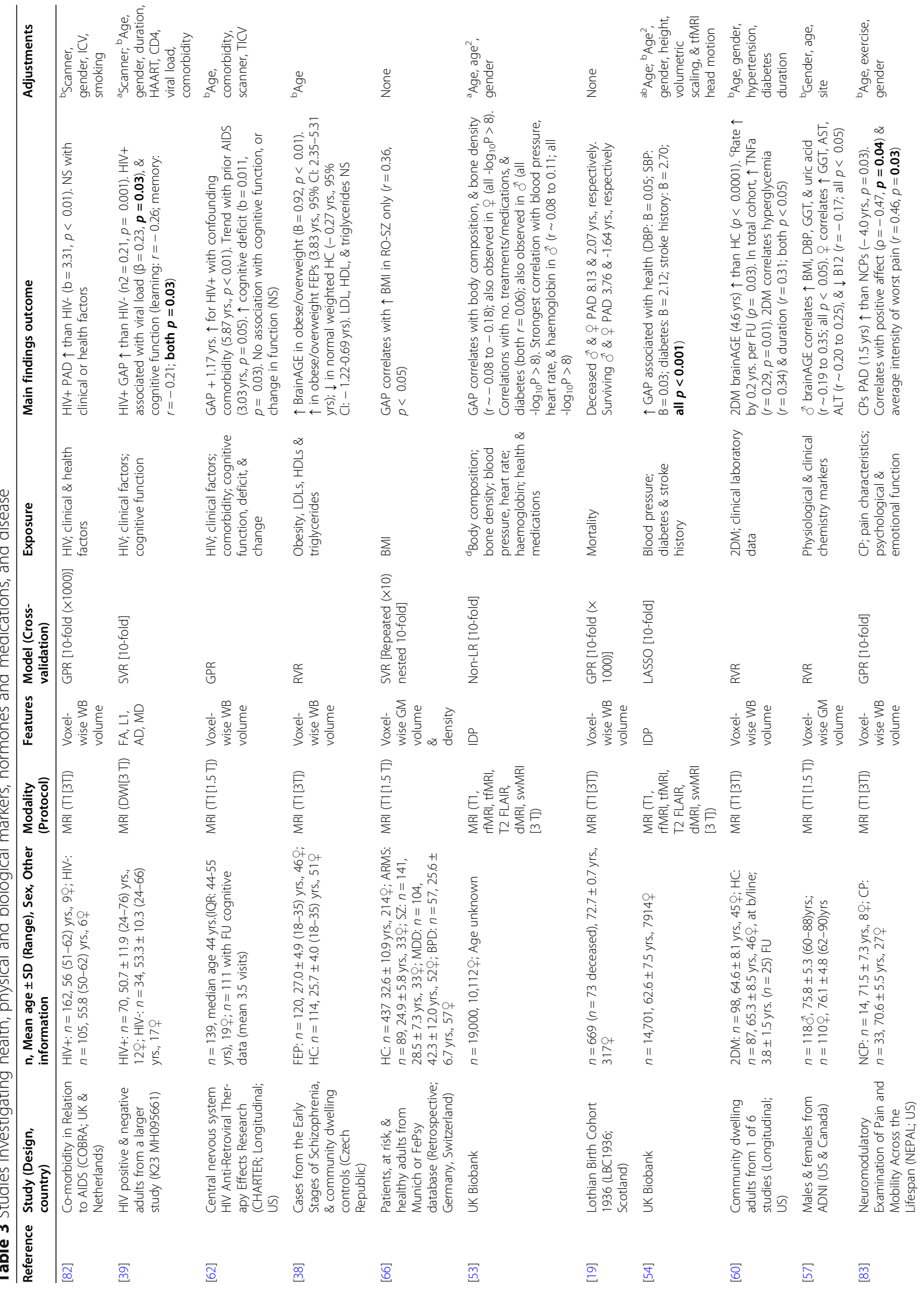




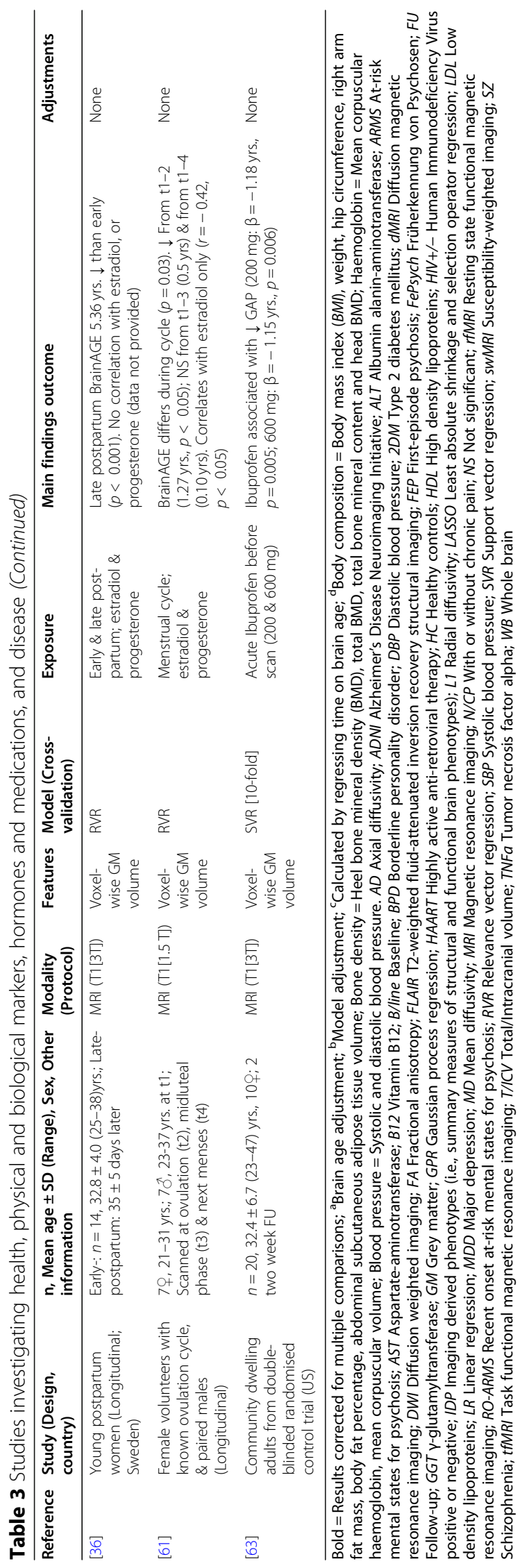




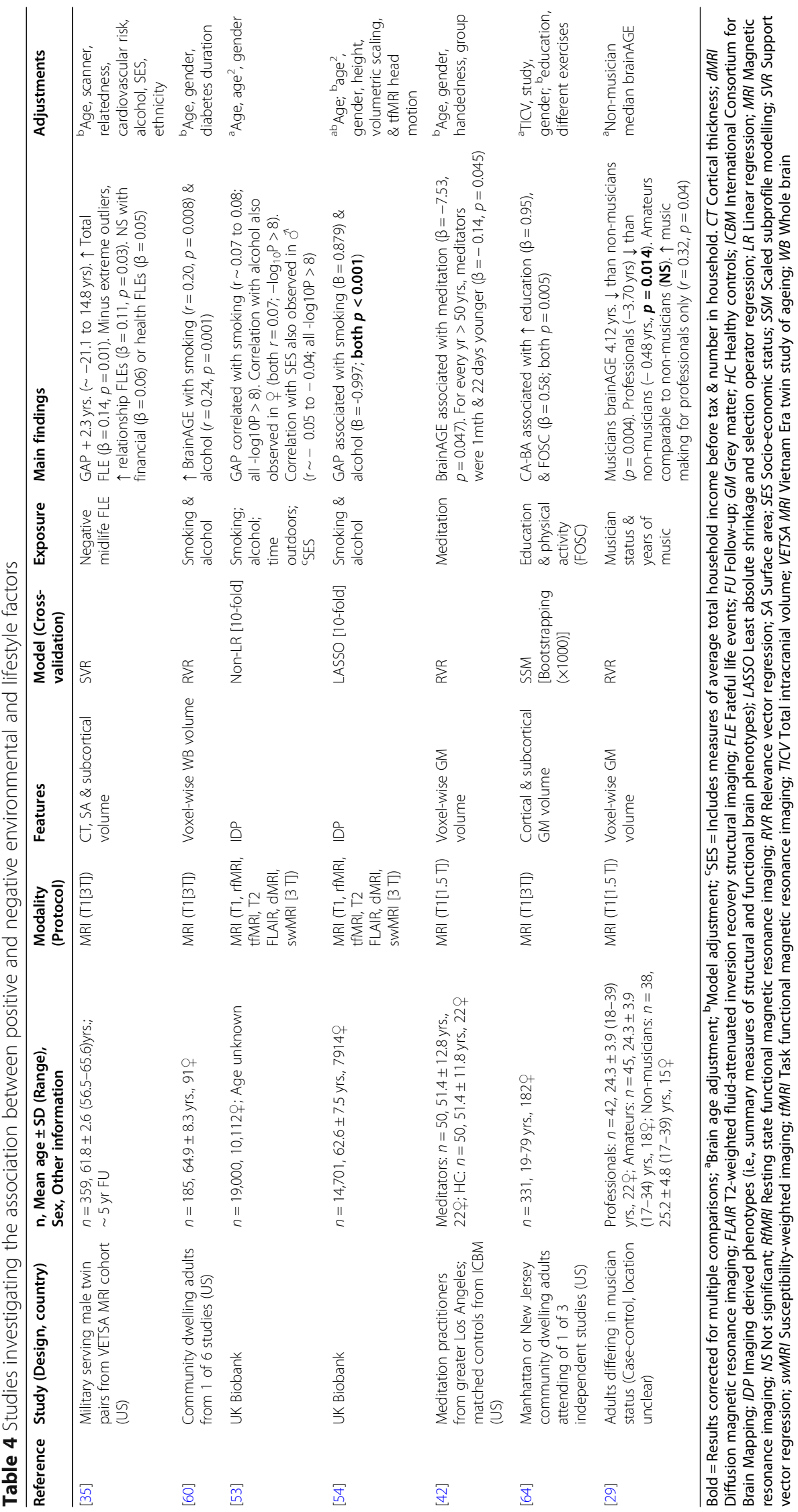




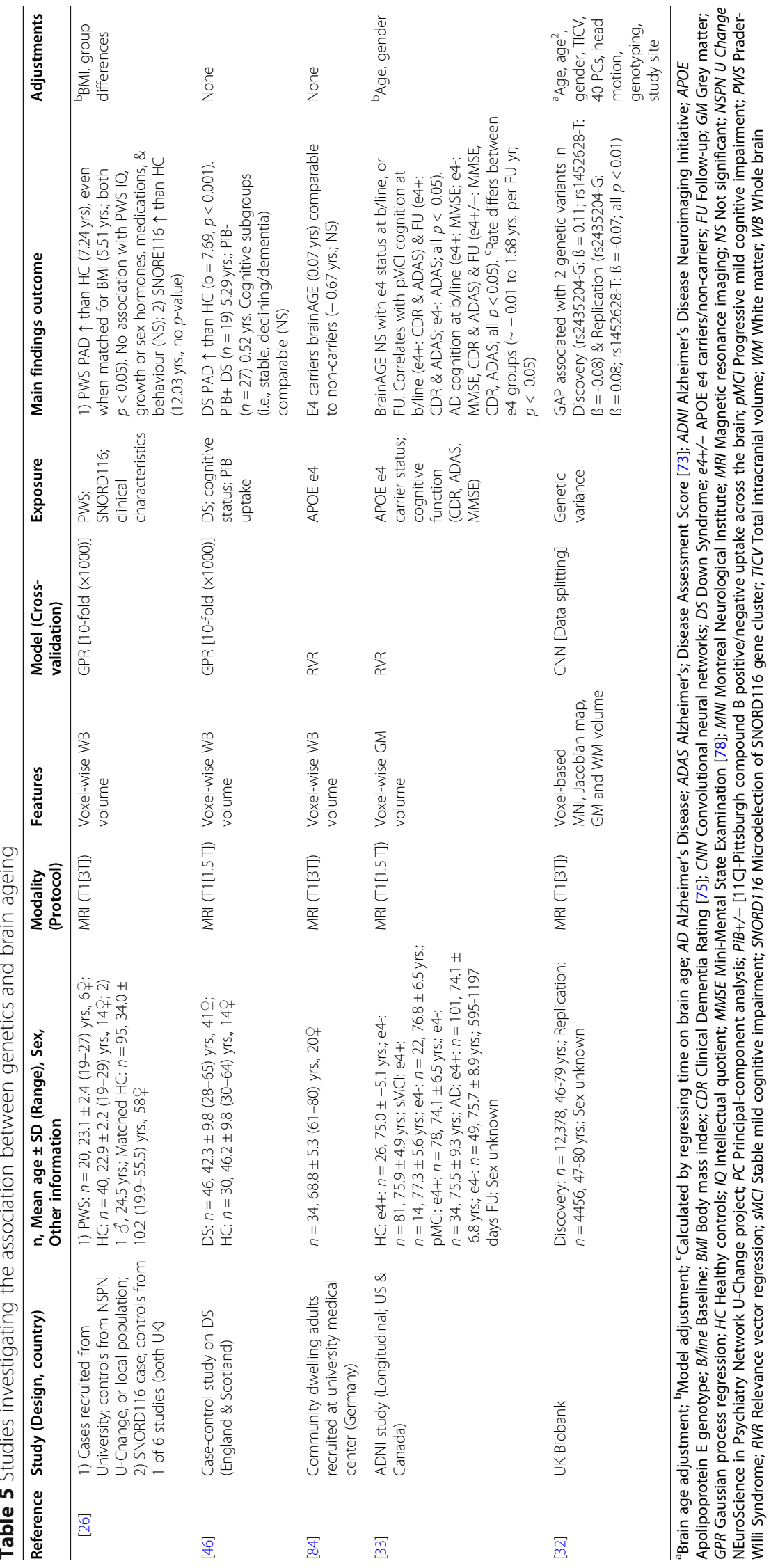




\section{Other factors in ageing populations}

Ten studies analysed brain ageing in relation to gender, race, cognitive function, and other measures of biological ageing (i.e., DNA methylation age, telomeres, physical and biological markers of health, and facial ageing) [19, 31], most investigated was cognitive function (Table 6). Six out of seven studies reported a significant association between brain ageing and cognitive function across different domains, most consistent were psychomotor and executive function [31, 32, 53, 54, 90]. The remaining seventh study observed no correlation with working memory, and was the only study to measure cognition via a functional MRI based-task [84].

Three studies analysed brain ageing using a large sample of participants from the UK Biobank (ranging between 12,378 to 19,000 participants), and reported a significant positive association with a single measure of psychomotor and executive function (i.e., as per the UK Biobank's Trail Making Task (TMT) B), despite applying different brain age algorithms [32, 53, 54]. However, only one of these three studies reported a significant positive association with all measures from the TMT (TMT-A, $-B$, and TMT minus B), but included fewer participants [32]. Two of these studies also observed a significant association with complex (i.e., Symbol Digit Substitution Test (DSST)) and simple psychomotor functions (i.e., Reaction time test), while the third had not included these two neuropsychological tests [54]. One additional study, measured brain ageing in three independent cohorts, and reported a significant association with psychomotor and executive function [90]. This same study also reported a significant association for two of the three cohorts that had used the same measure of executive function (i.e., TMT-B minus A) [90]. A fourth study, using longitudinal data (participants were assessed during childhood, and at 45 years of age), found a significant negative association with all measures of adult cognitive function and decline, including psychomotor function (i.e., as per the Wechsler Adult Intelligence Scale-IV, and DSST) [31, 93, 94].

Three studies investigated gender [19, 53, 65]. One study reported decelerated brain ageing for female participants that was significantly lower than the accelerated brain ageing in males [19]. Regardless of whether brain age was trained on males or females only, a second, larger cohort study consistently found decelerated brain ageing in females, that was significantly different to the accelerated brain ageing observed in males [65]. In contrast to these findings, a third study, involving fewer participants (108 and 76 females and males, respectively) estimated non-linear brain age, and found brain ageing in females to be 0.7 years higher than males, though the direction, and significance of this finding remains unclear [53].
Two studies analysed associations with alternative measures of biological ageing [31, 54]. By combining various biological and physical markers (e.g., blood pressure, total cholesterol), Elliot et al. (2019) [31] calculated the pace of ageing and found a significant positive association between this and brain ageing. This same study also reported a significant positive association with subjective measures of facial ageing (i.e., defined by a panel of 8 independent raters) [31]. In contrast, Cole et al. (2020a) [54] found no significant relationship between brain ageing and DNA methylation age (i.e., 'epigenetic clock') or telomere length.

\section{Risk of bias assessment}

Details regarding the risk of bias assessment are given in the Additional File 2: Tables S1 to 3. The 35 cohort studies had an overall low risk of bias. The most pertinent sources of potential bias were unclear recruitment and inclusion criteria, not applying or being clear on the methods used to validate brain ageing (the majority of these studies had referenced the validated, Franke et al. (2010) model [55]), and not adjusting for potential confounders. Two, however, had controlled for age or white matter hyperintensities during the development of the brain age model $[69,91]$. Three studies included multiple datasets with more than one study design (i.e., cohort and case-control) but had a similar, low level of bias $[30,41,47]$. Of the 18 studies with a case-control design, overall they had higher risk of bias than cohort studies, with the controls not often being comparable to cases (i.e., by confounders, primarily age and sex), and did not identify participants using the same criteria. Further, the method used to measure the exposure/s of interest differed between cases and controls. Only one RCT study design was included and was considered to be of a high quality [63].

\section{Discussion}

This systematic review identified 52 studies which examined the association between genetic, lifestyle, health factors and disease, and brain ageing (age-related changes of the brain defined by the deviation of neuroimaging predicted brain age relative to chronological age). Studies were grouped according to exposure types, with some covering more than one. The majority of evidence on brain ageing came from populations diagnosed with certain forms of mental health or neurological disorders, or cognitive function in normal ageing populations. Evidence regarding the association with lifestyle or environmental, and genetic factors was sparse. Most studies investigated brain ageing in smaller sub-samples of participants drawn from a larger cohort study (34 had one or more samples with less than 100 people) and thus were limited in their statistical sensitivity. Further, some 


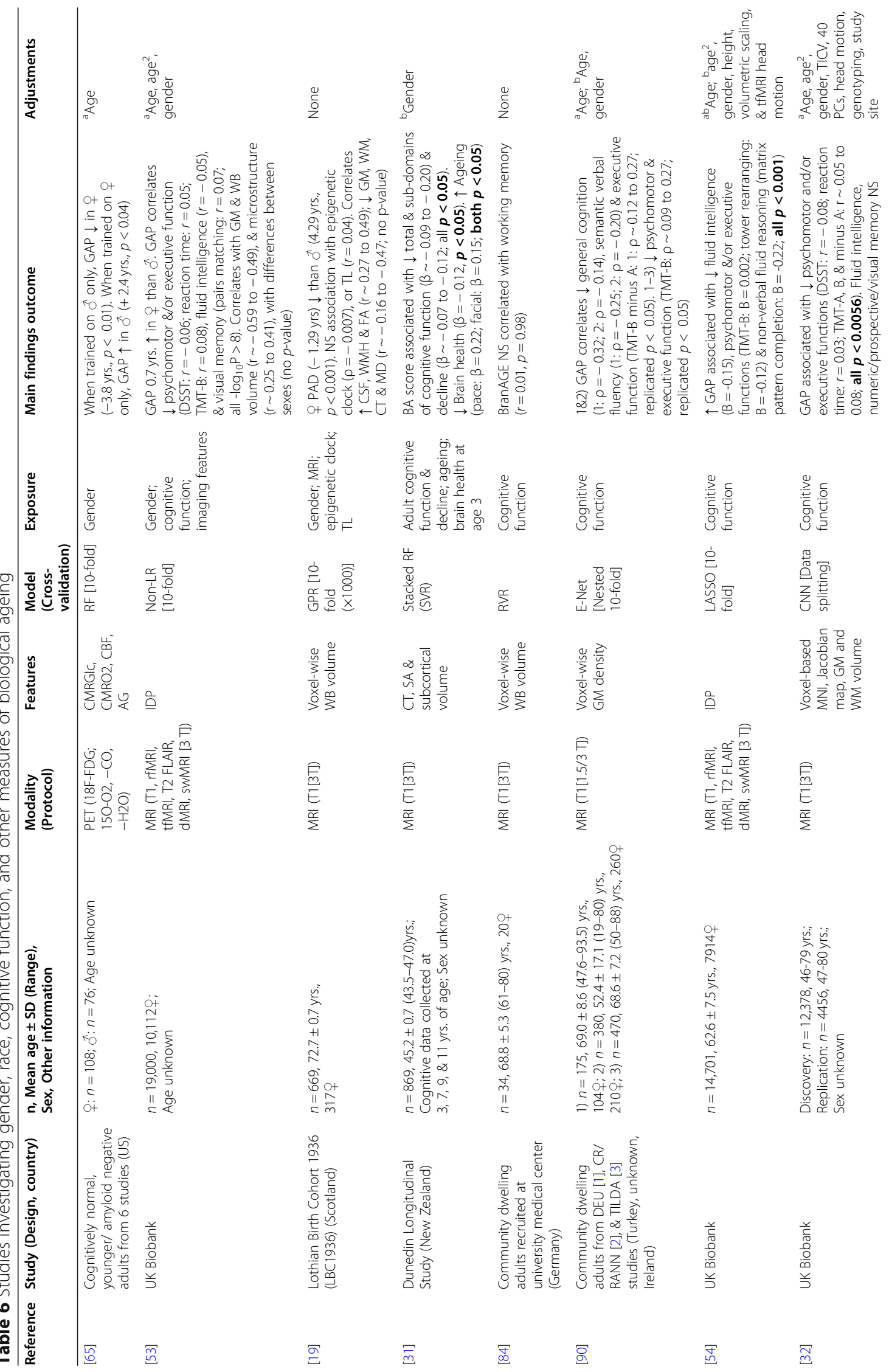




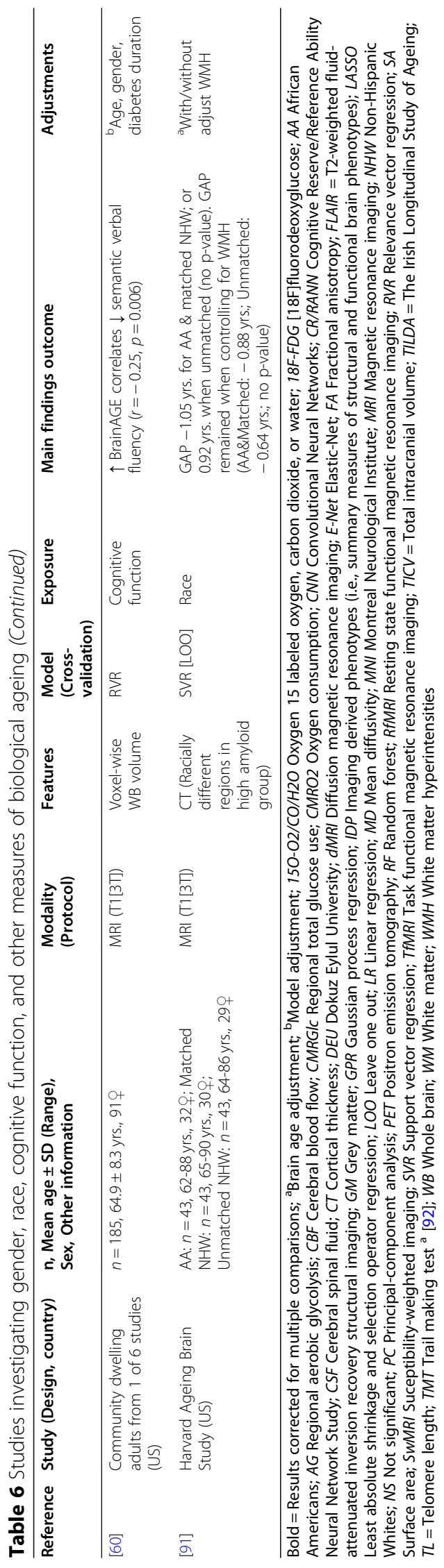


cohorts were a common source of participants for certain exposure types across multiple studies. Inconsistencies were evident for some exposure groups, but were partly attributed to the heterogeneity in study methodologies (i.e., either through design or participant characteristics) or methods of outcome ascertainment.

SZ was the most commonly studied of all exposures, and was consistently shown to be associated with more rapid brain ageing by studies with a relatively low to moderate risk of bias [27, 30, 32, 34, 41, 49, 66]. This is despite methodological differences between studies in terms of the neuroimaging features used to calculate brain ageing, such as cerebral perfusion [27], brain volume and/or density [30, 38, 41, 49, 66] and combinations of cortical thickness, fractional anisotropy, and cognitive performance scores [34]. This corroborates the neuroimaging literature, whereby brain changes overlap those observed in healthy ageing (reductions in brain volume, ventricular enlargement, and cortical thinning) [95-98]. However, concluding mechanisms still vary among studies (i.e., SZ is causative, or the consequence of accelerated ageing), and, in some accounts, limited by the cross-sectional design [27, 32, 34, 38, 41, 49]. Effect sizes vary among studies, and brain ageing in SZ was not always compared to healthy controls. Further, healthy controls deviated from the normal ageing trajectory for some studies, and thus effects may also reflect innate model biases, or the effects of other exposures on brain age prediction.

Evidence of more rapid brain ageing in $\mathrm{AD}$ compared to healthy controls was also relatively consistent. Brain atrophy (i.e., the loss of tissue volume) is common with age and is more severe in AD [9]. These findings of accelerated brain ageing corroborate evidence from neuroimaging studies [99, 100], and findings relating to other ageing biomarkers measured in brain tissue [101]. The positive association between brain ageing and disease symptom severity, and the progression from $\mathrm{MCI}$ to $\mathrm{AD}$, provides further evidence that $\mathrm{AD}$ is directly linked with brain ageing [33, 56, 58, 68]. Findings from two prospective studies also correspond with imaging studies that reported a greater rate of brain atrophy $(2 \%$ per year for $\mathrm{GM}$ volume) in $\mathrm{AD}$ patients $[33,56,102]$. An important limitation however, is that all studies of $\mathrm{AD}$ used data collected from the ADNI study, and thus, even if the final sample was different between studies, they cannot be considered as entirely independent $[33,56]$. Further, the studies only provide a global measure of brain ageing, and thus cannot inform on regional differences in ageing that have been extensively reported in the literature $[99,103,104]$.

Evidence across other exposures was relatively inconsistent, in particular with regards to gender and BMI $[53,57]$. Heterogeneity in brain age methodologies and participant characteristics are the likely cause of such discrepancies. For example, when investigating gender, two studies reporting preserved ageing in women both used linear models to estimate brain ageing, while the third used a non-linear algorithm, and reported preserved ageing in men. Though this evidence corroborates neuroimaging findings, the literature primarily relates to regional differences (which contrasts the whole brain estimates used by these two eligible studies), and is also relatively inconsistent [65, 105-111]. Further, all three studies had not accounted for potential confounding effects of other environmental exposures, that are specific to certain genders (e.g., education or occupation) and may explain discrepancies between studies, as they have also been associated with altered brain phenotypes [105]. This is a similar limitation when interpreting associations between BMI and brain ageing. BMI is routinely used as a measure of obesity, which is considered to have adverse effects on the brain, and cognitive function in both elderly and SZ populations [112-116]. However, it is attributed to a number of environmental factors (e.g., socioeconomic status, lower physical activity) that may act as confounders in these studies [117]. Study designs and participants varied greatly when investigating BMI as an exposure of brain ageing. Specifically, two of the four studies involved a cohort of older community dwelling participants $[53,57]$, while the remaining two were case-control studies investigating obesity in young adult populations with SZ $[38,66]$. Correlations were only reported by three of four studies investigating BMI, and show little to no relationship with brain ageing. Further, due to the cross-sectional nature of all studies on gender, and BMI, cause and effect relationships could not be determined.

Some studies investigated a number of lifestyle factors, and reported an association between education, physical activity and music with declines in brain ageing [29, 42, 64], while smoking and alcohol consumption were associated with accelerated ageing of the brain [37, 53, 54, 60]. This corroborates the literature, whereby positive lifestyle factors, like physical activity, are associated with preserved structural and functional integrity [118-120], and a reduced risk for $\mathrm{AD}$ [121], while smoking and alcohol are found to exacerbate a decline in brain phenotypes [122, 123]. Though this seems promising, the amount of evidence regarding brain ageing is still sparse. Further, studies are cross sectional, and thus temporal and causal relationships cannot be determined. Some studies were also underpowered, while others have limited generalisability (i.e., sampled data from the same cohort study).

Studies used a number of methods to calculate brain ageing. Most common was the framework proposed by Franke et al. (2010) [55] which utilises a relevance vector 
regression to estimate age from brain volume $[29,33,36$, $38,41,42,44,49,50,55-58,60,61,84]$. A large number of studies alternatively used the framework developed by Cole et al. (2015) [51], and thus the second most commonly used algorithm was the gaussian processes regression, primarily when estimating age from brain volume $[19,26,28,40,46,51,62,82,83]$. Considering the contribution by Franke and Cole to the field of brain ageing, the popularity of these frameworks is not surprising. Despite recommendations [124], few studies used multimodal approaches to estimate brain age, which may reflect the popularity of these single modal models; though the need for multiple acquisitions, and greater burden to elderly participants, may have also played a role $[34,53,54,67$, $69,125]$. Despite a rising interest in deep learning [126, 127], only one study used a convolutional neural network to calculate brain ageing [32].

\section{Strengths and limitations of review}

This systematic review was conducted in accordance with PRISMA guidelines (http://www.prisma-statement. org) [22]. To ensure all relevant publications were included, a systematic search of the brain ageing literature was undertaken, and directed by a registered eligibility criterion, and involved databases and additional literature reviews [20, 21]. Including general and clinical populations increased the coverage exposure types, and thus findings will be of interest to a greater array of research fields. This was also achieved by the inclusion of all neuroimaging modalities and feature types, and reduces any bias towards brain age frameworks that are developed from specific phenotypes (e.g., brain volume, as per Franke et al. (2010) [55] \& Cole et al. (2015) [51]).

There are limitations to this systematic review that should be addressed. Considering the contribution of conference papers to machine learning research, the removal of this literary source may have reduced the number of identified papers, and thus influenced the conclusions for this systematic review. The accuracy and generalisability of age prediction were not reported, nor were details regarding the training sample.

\section{Further directions}

This systematic review identified a number of gaps in the brain ageing literature that should be addressed through future research efforts. So far, supervised machine learning is the most popular approach to define brain ageing, particularly when using brain volume as a feature. Comparatively few studies have pursued deep learning approaches to estimating brain ageing. Though they are computationally intensive, there are many benefits that could overcome limitations imposed by other machine learning algorithms, such as the ability to use raw neuroimaging data as input [126, 127]. Clinically, this an appealing option as it is more time efficient (i.e., as no pre-processing is required), and requires little computational engineering $[127,128]$. Like deep learning, few studies used multimodal approaches for estimating brain age. Though there are challenges in acquiring, and combining multiple data types; features of various brain phenotypes (obtained from various modalities) could be more informative, and thus may be a more comprehensive approach to investigating brain ageing $[125,129]$.

Few studies used prospective data, and thus could not investigate cause and effect relationships. Longitudinal studies will help overcome this limitation, and will address questions regarding whether brain age is a biomarker of ageing or disease, thus meeting a key criterion proposed by The American Federation for Ageing Research (i.e., biomarkers must monitor ageing processes, not disease) [130].

The evidence regarding the effects of environmental and lifestyle factors on brain ageing is sparse. Identifying interventions and treatments that are brain preserving, and thus slow the ageing process, is useful knowledge for the ever-growing ageing population, and has many clinical implications, like reducing the strain on age care facilities.

Results regarding brain ageing and gender or BMI were inconsistent. Heterogenous brain ageing methodologies, study designs, and participant characteristics were identified as the likely cause. Thus, to confirm whether findings reflect a true ageing effect, future studies should focus their efforts on replicating these methods, and sampling from populations that are characteristically similar. Information on whether brain ageing is sensitive to gender, or BMI, could help inform certain populations at risk, and be used to prevent poor health outcomes.

Finally, only two eligible studies compared, or combined, brain ageing to alternative ageing biomarkers [19, 31]. It remains unclear whether ageing is tissue specific, or a systematic process, and thus additional knowledge from studies comparing brain ageing with other ageing biomarkers could help resolve this question.

\section{Conclusion}

This systematic review summarised the current evidence for an association between genetic, lifestyle, health, or diseases and brain ageing, the most common being schizophrenia, followed by Alzheimer's disease. Overall, there is good evidence to suggest schizophrenia is associated with accelerated brain ageing, but limited, or mixed evidence for all other exposures examined. In most cases this was due to a lack of independent replication and consistency across multiple studies that were primarily cross sectional in nature. Thus, future research efforts should focus on replicating current findings, using prospective datasets, to further clarify exposures that may have age preserving, or accelerating properties. 


\section{Abbreviations}

AD: Alzheimer's disease; ADAS: Alzheimer's disease assessment scale; ADNI: Alzheimer's disease; neuroimaging initiative; APOE: Apolipoprotein $E_{;}$ BMI: Body mass index; CDR: Clinical dementia rating; HIV: Human immunodeficiency virus; MCl: Mild cognitive impairment; MD: Major depression; MMSE: Mini-mental state examination; MRE: Medical refractory epilepsy; MRI: Magnetic resonance imaging; MS: Multiple sclerosis; NDE: Newly diagnosed focal epilepsy; DSST: Symbol digit substitution test; SZ: Schizophrenia; TMT: Trail making task; TBI: Traumatic brain injury

\section{Supplementary Information}

The online version contains supplementary material available at https://doi. org/10.1186/s12883-021-02331-4.

\section{Additional file 1:. Completed Prisma 2009 checklist}

Additional file 2: Supplementary Results. Risk of bias assessment Tables S1-3.

\section{Acknowledgements}

Not applicable.

\section{Authors' contributions}

JW conducted the initial literature search; screened articles for eligibility and risk of bias; extracted and synthesised data, and wrote the manuscript. ZW, and DN screened articles for eligibility, and assessed risk of bias. To resolve discrepancies, JR was the third reviewer during article screening, and risk of bias assessment. PW, IHH, and RLW reviewed draft manuscripts. All authors read and approved the final manuscript.

\section{Funding}

This work was supported by a Research Training Program stipend, awarded by Monash University and the Australian government to JW, DN, and ZW the National Health and Medical Research Council (NHMRC) Fellowship (1106533 to $\mathrm{IHH}$ ); and the NHMRC Dementia Research Leader Fellowship (1135727 to JR). Funders did not direct the conduction of this systematic review, nor the decision to publish these findings.

\section{Availability of data and materials}

All data generated or analysed during this study are included in this published article and its supplementary information files.

\section{Declarations}

\section{Ethics approval and consent to participate}

Not applicable.

\section{Consent for publication}

Not applicable.

\section{Competing interests}

The authors declare that they have no competing interests.

\section{Author details}

${ }^{1}$ School of Public Health and Preventive Medicine, Monash University, Melbourne, Victoria 3004, Australia. ${ }^{2}$ Monash Biomedical Imaging, Monash University, Clayton, Victoria 3168, Australia. ${ }^{3}$ Turner Institute for Brain and Mental Health, Monash University, Clayton, Victoria 3800, Australia. ${ }^{4}$ Australian Research Council Centre of Excellence for Integrative Brain Function, Clayton, Victoria 3800, Australia. ${ }^{5}$ Department of Neuroscience, Central Clinical School, Monash University, Melbourne, Victoria 3004, Australia.

Received: 18 January 2021 Accepted: 24 June 2021

Published online: 12 August 2021

\section{References}

1. Lopez-Otin C, Blasco MA, Partridge L, Serrano M, Kroemer G. The hallmarks of aging. Cell. 2013;153(6):1194-217. https:/doi.org/10.1016/j.cell.2013.05.039.

2. Kirkwood TB. Understanding the odd science of aging. Cell. 2005;120(4): 437-47. https://doi.org/10.1016/j.cell.2005.01.027.
3. Kirkwood TB. A systematic look at an old problem. Nature. 2008;451(7179): 644-7. https://doi.org/10.1038/451644a.

4. Organization WH. Active ageing: a policy framework, vol. 2015. Geneva: World Health Organization; 2002. WHO/NMP/NPH/02.8.

5. Anderton $\mathrm{BH}$. Changes in the ageing brain in health and disease. Philos Trans R Soc Lond Ser B Biol Sci. 1997;352(1363):1781-92. https://doi.org/10.1 098/rstb.1997.0162.

6. Anderton BH. Ageing of the brain. Mech Ageing Dev. 2002;123(7):811-7. https://doi.org/10.1016/S0047-6374(01)00426-2.

7. Damoiseaux JS. Effects of aging on functional and structural brain connectivity. Neuroimage. 2017;160:32-40. https://doi.org/10.1016/j. neuroimage.2017.01.077

8. Ferreira LK, Busatto GF. Resting-state functional connectivity in normal brain aging. Neurosci Biobehav Rev. 2013;37(3):384-400. https://doi.org/10.1016/j. neubiorev.2013.01.017.

9. Grajauskas LA, Siu W, Medvedev G, Guo H, D'Arcy RCN, Song X. MRI-based evaluation of structural degeneration in the ageing brain: pathophysiology and assessment. Ageing Res Rev. 2019;49:67-82. https://doi.org/10.1016/j.a rr.2018.11.004.

10. Fjell AM, Westlye LT, Grydeland H, Amlien I, Espeseth T, Reinvang I, et al. Accelerating cortical thinning: unique to dementia or universal in aging? Cereb Cortex. 2014;24(4):919-34. https://doi.org/10.1093/cercor/bhs379.

11. Fotenos AF, Snyder AZ, Girton LE, Morris JC, Buckner RL. Normative estimates of cross-sectional and longitudinal brain volume decline in aging and AD. Neurology. 2005;64(6):1032-9. https://doi.org/10.1212/01.WNL. 0000154530.72969 .11

12. Storsve AB, Fjell AM, Tamnes CK, Westlye LT, Overbye K, Aasland HW, et al. Differential longitudinal changes in cortical thickness, surface area and volume across the adult life span: regions of accelerating and decelerating change. J Neurosci. 2014;34(25):8488-98. https://doi.org/10.1523/JNEUROSCI. 0391-14.2014.

13. Bennett IJ, Madden DJ. Disconnected aging: cerebral white matter integrity and age-related differences in cognition. Neuroscience. 2014;276:187-205. https://doi.org/10.1016/j.neuroscience.2013.11.026.

14. Bonifazi P, Erramuzpe A, Diez I, Gabilondo I, Boisgontier MP, Pauwels L, et al. Structure-function multi-scale connectomics reveals a major role of the fronto-striato-thalamic circuit in brain aging. Hum Brain Mapp. 2018;39(12): 4663-77. https://doi.org/10.1002/hbm.24312.

15. Fjell AM, Walhovd KB. Structural brain changes in aging: courses, causes and cognitive consequences. Rev Neurosci. 2010;21(3):187-221. https://doi.org/1 0.1515/revneuro.2010.21.3.187.

16. Gunning-Dixon FM, Brickman AM, Cheng JC, Alexopoulos GS. Aging of cerebral white matter: a review of MRI findings. Int J Geriatr Psychiatry. 2009;24(2):109-17. https://doi.org/10.1002/gps.2087.

17. Vieira S, Pinaya WH, Mechelli A. Using deep learning to investigate the neuroimaging correlates of psychiatric and neurological disorders: Methods and applications. Neurosci Biobehav Rev. 2017;74(Pt A):58-75.

18. Cole JH, Marioni RE, Harris SE, Deary IJ. Brain age and other bodily 'ages': implications for neuropsychiatry. Mol Psychiatry. 2019;24(2):266-81. https://doi.org/10.1038/s41380-018-0098-1.

19. Cole JH, Ritchie SJ, Bastin ME, Valdes Hernandez MC, Munoz Maniega S, Royle N, et al. Brain age predicts mortality. Mol Psychiatry. 2018;23(5):1385-92. https://doi.org/10.1038/mp.2017.62.

20. Franke K, Gaser C. Ten years of BrainAGE as a neuroimaging biomarker of brain aging: what insights have we gained? Front Neurol. 2019;10:789. https://doi.org/10.3389/fneur.2019.00789.

21. Cole JH, Franke K, Cherbuin N. Quantification of the biological age of the brain using neuroimaging. In: Biomarkers of human aging. Cham: Springer International Publishing; 2019. p. 293-328. https://doi.org/10.1007/978-3-03 0-24970-0_19.

22. Moher D, Liberati A, Tetzlaff J, Altman DG, Group P. Preferred reporting items for systematic reviews and meta-analyses: the PRISMA statement. PLoS Med. 2009;6(7):e1000097. https://doi.org/10.1371/journal.pmed.1000097.

23. Adluru N, Korponay CH, Norton DL, Goldman RI, Davidson RJ. BrainAGE and regional volumetric analysis of a Buddhist monk: a longitudinal MRI case study. Neurocase. 2020;26(2):79-90. https://doi.org/10.1080/13554794.2020.1731553.

24. Ronan L, Alexander-Bloch AF, Wagstyl K, Farooqi S, Brayne C, Tyler LK, et al. Obesity associated with increased brain age from midlife. Neurobiol Aging. 2016;47:63-70. https://doi.org/10.1016/j.neurobiolaging.2016.07.010.

25. Institute JB. Joanna Briggs institute reviewers' manual: 2014 edition. Australia: The Joanna Briggs Institute; 2014. 
26. Azor AM, Cole JH, Holland AJ, Dumba M, Patel MC, Sadlon A, et al. Increased brain age in adults with Prader-Willi syndrome. Neuroimage Clin 2019;21:101664. https://doi.org/10.1016/j.nicl.2019.101664.

27. Amen DG, Egan S, Meysami S, Raji CA, George N. Patterns of regional cerebral blood flow as a function of age throughout the lifespan. J Alzheimers Dis. 2018;65(4):1087-92. https://doi.org/10.3233/JAD-180598.

28. Cole JH, Raffel J, Friede T, Eshaghi A, Brownlee WJ, Chard D, et al. Longitudinal assessment of multiple sclerosis with the brain-age paradigm Ann Neurol. 2020b;14:93-105.

29. Rogenmoser L, Kernbach J, Schlaug G, Gaser C. Keeping brains young with making music. Brain Struct Funct. 2018;223(1):297-305. https://doi.org/10.1 007/s00429-017-1491-2.

30. Schnack HG, Van Haren NEM, Nieuwenhuis M, Pol HEH, Cahn W, Kahn RS. Accelerated brain aging in schizophrenia: a longitudinal pattern recognition study. Am J Psychiatry. 2016;173(6):607-16. https://doi.org/10.1176/appi.ajp.2 015.15070922

31. Elliott ML, Belsky DW, Knodt AR, Ireland D, Melzer TR, Poulton R, et al. Brainage in midlife is associated with accelerated biological aging and cognitive decline in a longitudinal birth cohort. Mol Psychiatry. 2019. Online ahead of print.

32. Jonsson BA, Bjornsdottir G, Thorgeirsson TE, Ellingsen LM, Walters GB, Gudbjartsson DF, et al. Brain age prediction using deep learning uncovers associated sequence variants. Nat Commun. 2019;10(1):5409. https://doi. org/10.1038/s41467-019-13163-9.

33. Lowe LC, Gaser C, Franke K. The effect of the APOE genotype on individual BrainAGE in normal aging, Mild cognitive impairment, and Alzheimer's Disease. PLoS One. 2016;11(7):e0157514.

34. Shahab S, Mulsant BH, Levesque ML, Calarco N, Nazeri A, Wheeler AL, et al. Brain structure, cognition, and brain age in schizophrenia, bipolar disorder and healthy controls. Neuropsychopharmacology. 2019;44(5):898-906. https://doi.org/10.1038/s41386-018-0298-z.

35. Hatton SN, Franz CE, Elman JA, Panizzon MS, Hagler DJ Jr, FennemaNotestine C, et al. Negative fateful life events in midlife and advanced predicted brain aging. Neurobiol Aging. 2018;67:1-9. https://doi.org/10.101 6/j.neurobiolaging.2018.03.004.

36. Luders E, Gingnell M, Poromaa IS, Engman J, Kurth F, Gaser C. Potential brain age reversal after pregnancy: younger brains at 4-6Weeks postpartum. Neuroscience. 2018;386:309-14. https://doi.org/10.1016/j.neuroscience.2018. 07.006.

37. Guggenmos M, Schmack K, Sekutowicz M, Garbusow M, Sebold M, Sommer C, et al. Quantitative neurobiological evidence for accelerated brain aging in alcohol dependence. Transl Psychiatry. 2017;7(12):1279. https://doi.org/10.1 038/s41398-017-0037-y.

38. Kolenic M, Franke K, Hlinka J, Matejka M, Capkova J, Pausova Z, et al. Obesity, dyslipidemia and brain age in first-episode psychosis. J Psychiatr Res. 2018;99:151-8. https://doi.org/10.1016/j.jpsychires.2018.02.012

39. Kuhn T, Kaufmann T, Doan NT, Westlye LT, Jones J, Nunez RA, et al. An augmented aging process in brain white matter in HIV. Hum Brain Mapp. 2018:39(6):2532-40. https://doi.org/10.1002/hbm.24019.

40. Pardoe HR, Cole JH, Blackmon K, Thesen T, Kuzniecky R. Structural brain changes in medically refractory focal epilepsy resemble premature brain aging. Epilepsy Res. 2017;133:28-32. https://doi.org/10.1016/j.eplepsyres.20 7.03.007.

41. Hajek T, Franke K, Kolenic M, Capkova J, Matejka M, Propper L, et al. Brain age in early stages of bipolar disorders or schizophrenia. Schizophr Bull. 2019;45(1):190-8. https://doi.org/10.1093/schbul/sbx172.

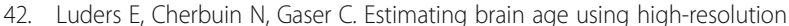
pattern recognition: younger brains in long-term meditation practitioners. Neuroimage. 2016;134:508-13. https://doi.org/10.1016/j.neuroimage.2016.04.007.

43. Han LKM, Dinga R, Hahn T, Ching CRK, Eyler LT, Aftanas L, et al. Brain aging in major depressive disorder: results from the ENIGMA major depressive disorder working group. Mol Psychiatry. 2020;1-16.https://doi.org/10.1038/ s41380-020-0754-0

44. Besteher B, Gaser C, Nenadic I. Machine-learning based brain age estimation in major depression showing no evidence of accelerated aging. Psychiatry Res Neuroimaging. 2019;290:1-4. https://doi.org/10.1016/j.pscychresns.2019. 06.001.

45. Chen $\mathrm{CL}$, Shih YC, Liou HH, Hsu YC, Lin FH, Tseng WYI. Premature white matter aging in patients with right mesial temporal lobe epilepsy: A machine learning approach based on diffusion MRI data. Neurolmage Clin. 2019;24:102033.
46. Cole JH, Annus T, Wilson LR, Remtulla R, Hong YT, Fryer TD, et al. Brainpredicted age in Down syndrome is associated with beta amyloid deposition and cognitive decline. Neurobiol Aging. 2017c;56:41-9. https://doi.org/10.1016/.j.neurobiolaging.2017.04.006.

47. Hogestol EA, Kaufmann T, Nygaard GO, Beyer MK, Sowa P, Nordvik JE, et al. Cross-sectional and longitudinal MRI brain scans reveal accelerated brain aging in multiple sclerosis. Front Neurol. 2019;10:450.

48. Moeller JR, Eidelberg D. Divergent expression of regional metabolic topographies in Parkinson's disease and normal ageing. Brain. 1997;1:2197206.

49. Nenadic I, Dietzek M, Langbein K, Sauer H, Gaser C. BrainAGE score indicates accelerated brain aging in schizophrenia, but not bipolar disorder. Psychiatry Res. 2017;266:86-9. https://doi.org/10.1016/j.pscychresns.2017. 05.006 .

50. Van Gestel H, Franke K, Petite J, Slaney C, Garnham J, Helmick C, et al. Brain age in bipolar disorders: effects of lithium treatment. Aust N Z J Psychiatry. 2019:53(12):1179-88

51. Cole JH, Leech R, Sharp DJ. Prediction of brain age suggests accelerated atrophy after traumatic brain injury. Ann Neurol. 2015;77(4):571-81. https:// doi.org/10.1002/ana.24367.

52. Sone D, Beheshti I, Maikusa N, Ota M, Kimura Y, Sato N, et al. Neuroimaging-based brain-age prediction in diverse forms of epilepsy: a signature of psychosis and beyond. Mol Psychiatry. 2019;26(3):825-34.

53. Smith SM, Vidaurre D, Alfaro-Almagro F, Nichols TE, Miller KL. Estimation of brain age delta from brain imaging. Neurolmage. 2019;12:528-39.

54. Cole JH. Multimodality neuroimaging brain-age in UK biobank: relationship to biomedical, lifestyle, and cognitive factors. Neurobiol Aging. 2020a;92:3442. https://doi.org/10.1016/j.neurobiolaging.2020.03.014.

55. Franke K, Ziegler G, Kloppel S, Gaser C. Alzheimer's disease neuroimaging I. estimating the age of healthy subjects from T1-weighted MRI scans using kernel methods: exploring the influence of various parameters. Neuroimage. 2010:50(3):883-92. https://doi.org/10.1016/j.neuroimage.2010.01.005.

56. Franke K, Gaser C. Longitudinal changes in individual BrainAGE in healthy aging, mild cognitive impairment, and Alzheimer's disease. GeroPsych J Gerontopsychol Geriatr Psychiatry. 2012;25(4):235-45. https://doi.org/10.1 024/1662-9647/a000074.

57. Franke K, Ristow M, Gaser C. Gender-specific impact of personal health parameters on individual brain aging in cognitively unimpaired elderly subjects. Front Aging Neurosci. 2014;6:94.

58. Gaser C, Franke K, Kloppel S, Koutsouleris N, Sauer H. BrainAGE in mild cognitive impaired patients: predicting the conversion to alzheimer's disease. PLoS One. 2013;8(6):e67346.

59. Egorova N, Liem F, Hachinski V, Brodtmann A. Predicted brain age after stroke. Front Aging Neurosci. 2019;11:348.

60. Franke K, Gaser C, Manor B, Novak V. Advanced BrainAGE in older adults with type 2 diabetes mellitus. Front Aging Neurosci. 2013;5:90.

61. Franke K, Hagemann G, Schleussner E, Gaser C. Changes of individual BrainAGE during the course of the menstrual cycle. Neuroimage. 2015;115: 1-6. https://doi.org/10.1016/j.neuroimage.2015.04.036.

62. Underwood J, Cole JH, Leech R, Sharp DJ, Winston A. Group C. multivariate pattern analysis of volumetric neuroimaging data and its relationship with cognitive function in treated HIV disease. J Acquir Immune Defic Syndr. 2018;78(4):429-36. https://doi.org/10.1097/QAl.0000000000001687.

63. Le TT, Kuplicki R, Yeh HW, Aupperle RL, Khalsa SS, Simmons WK, et al. Effect of ibuprofen on BrainAGE: a randomized, placebo-controlled, dose-response exploratory study. Biolog Psychiatry. 2018;3(10):836-43.

64. Steffener J, Habeck C, O'Shea D, Razlighi Q, Bherer L, Stern Y. Differences between chronological and brain age are related to education and selfreported physical activity. Neurobiol Aging. 2016:40:138-44. https://doi.org/1 0.1016/j.neurobiolaging.2016.01.014

65. Goyal MS, Blazey TM, Su Y, Couture LE, Durbin TJ, Bateman RJ, et al. Persistent metabolic youth in the aging female brain. Proc Natl Acad Sci $U$ S A. 2019;116(8):3251-5. https://doi.org/10.1073/pnas.1815917116.

66. Koutsouleris N, Davatzikos C, Borgwardt S, Gaser C, Bottlender R, Frodl T, et al. Accelerated brain aging in schizophrenia and beyond: a neuroanatomical marker of psychiatric disorders. Schizophr Bull. 2014;40(5): 1140-53. https://doi.org/10.1093/schbul/sbt142.

67. Liem F, Varoquaux G, Kynast J, Beyer F, Kharabian Masouleh S, Huntenburg $J M$, et al. Predicting brain-age from multimodal imaging data captures cognitive impairment. Neuroimage. 2017;148:179-88. https://doi.org/10.101 6/j.neuroimage.2016.11.005. 
68. Beheshti I, Maikusa N, Matsuda H. The association between "brain-age score" (BAS) and traditional neuropsychological screening tools in Alzheimer's disease. Brain Behav. 2018;8(8):e01020. https://doi.org/10.1002/ brb3.1020.

69. Hwang G, Hermann B, Nair VA, Conant LL, Dabbs K, Mathis J, et al. Brain aging in temporal lobe epilepsy: Chronological, structural, and functional. Neurolmage Clin. 2020;25:102183.

70. Savjani RR, Taylor BA, Acion L, Wilde EA, Jorge RE. Accelerated changes in cortical thickness measurements with age in military service members with traumatic brain injury. J Neurotrauma. 2017;34(22):3107-16. https://doi.org/1 0.1089/neu.2017.5022.

71. Richard G, Kolskar K, Ulrichsen KM, Kaufmann T, Alnaes D, Sanders AM, et al. Brain age prediction in stroke patients: Highly reliable but limited sensitivity to cognitive performance and response to cognitive training. Neurolmage Clin. 2020;25:102159.

72. Mohs RC. The Alzheimer's disease assessment scale. Int Psychogeriatr. 1996; 8(2):195-203. https://doi.org/10.1017/S1041610296002578

73. Mohs RC, Cohen L. Alzheimer's disease assessment scale (ADAS). Psychopharmacol Bull. 1988;24(4):627-8

74. Mohs RC, Rosen WG, Davis KL. The Alzheimer's disease assessment scale: an instrument for assessing treatment efficacy. Psychopharmacol Bull. 1983; 19(3):448-50.

75. Morris JC. The clinical dementia rating (CDR): current version and scoring rules. Neurology. 1993;43(11):2412-4. https://doi.org/10.1212/ wnl.43.11.2412-a.

76. Kurtzke JF. Rating neurologic impairment in multiple sclerosis: an expanded disability status scale (EDSS). Neurology. 1983;33(11):1444-52. https://doi. org/10.1212/WNL.33.11.1444

77. Fillenbaum GG, Smyer MA. The development, validity, and reliability of the OARS multidimensional functional assessment questionnaire. J Gerontol. 1981;36(4):428-34. https://doi.org/10.1093/geronj/36.4.428.

78. Cockrell JR, Folstein MF. Mini-mental state examination (MMSE). Psychopharmacol Bull. 1988;24(4):689-92.

79. Folstein MF, Folstein SE, McHugh PR. "Mini-mental state". A practical method for grading the cognitive state of patients for the clinician. J Psychiatr Res. 1975;12(3):189-98. https://doi.org/10.1016/0022-3956(75)90026-6.

80. Kanemoto K, LaFrance WC Jr, Duncan R, Gigineishvili D, Park SP, Tadokoro Y, et al. PNES around the world: where we are now and how we can close the diagnosis and treatment gaps-an ILAE PNES task force report. Epilepsia Open. 2017:2(3):307-16. https://doi.org/10.1002/epi4.12060.

81. Thompson AJ, Banwell BL, Barkhof F, Carroll WM, Coetzee T, Comi G, et al. Diagnosis of multiple sclerosis: 2017 revisions of the McDonald criteria. Lancet Neurol. 2018;17(2):162-73. https://doi.org/10.1016/S1474-4422 (17)30470-2.

82. Cole JH, Underwood J, Caan MWA, De Francesco D, Van Zoest RA, Leech R, et al. Increased brain-predicted aging in treated HIV disease. Neurology. 2017b;88(14):1349-57. https://doi.org/10.1212/WNL.0000000000003790.

83. Cruz-Almeida Y, Fillingim RB, Riley JL, Woods AJ, Porges E, Cohen R, et al. Chronic pain is associated with a brain aging biomarker in communitydwelling older adults. Pain. 2019;160(5):1119-30. https://doi.org/10.1097/j.pa in.0000000000001491.

84. Scheller E, Schumacher LV, Peter J, Lahr J, Wehrle J, Kaller CP, et al. Brain aging and APOE epsilon4 interact to reveal potential neuronal compensation in healthy older adults. Front Aging Neurosci. 2018;10:74.

85. Frost B, Gotz J, Feany MB. Connecting the dots between tau dysfunction and neurodegeneration. Trends Cell Biol. 2015;25(1):46-53. https://doi.org/1 0.1016/j.tcb.2014.07.005.

86. Hedl TJ, San Gil R, Cheng F, Rayner SL, Davidson JM, De Luca A, et al. Proteomics approaches for biomarker and drug target discovery in ALS and FTD. Front Neurosci. 2019:13:548. https://doi.org/10.3389/fnins.2019.00548.

87. Bittner S, Ruck T, Fernandez-Orth J, Meuth SG. TREK-king the blood-brainbarrier. J Neurolmmune Pharmacol. 2014;9(3):293-301. https://doi.org/10.1 007/s11481-014-9530-8.

88. Cai Y, Peng Z, Guo H, Wang F, Zeng Y. TREK-1 pathway mediates isofluraneinduced memory impairment in middle-aged mice. Neurobiol Learn Mem. 2017;145:199-204. https://doi.org/10.1016/j.nlm.2017.10.012

89. Wang W, Liu D, Xiao Q, Cai J, Feng N, Xu S, et al. Lig4-4 selectively inhibits TREK-1 and plays potent neuroprotective roles in vitro and in rat MCAO model. Neurosci Lett. 2018;671:93-8. https://doi.org/10.1016/j.neulet.2018.02.015.

90. Boyle R, Jollans L, Rueda-Delgado LM, Rizzo R, Yener GG, McMorrow JP, et al. Brain-predicted age difference score is related to specific cognitive functions: a multi-site replication analysis. Brain Imaging Behavior. 2020; 15(1):327-45.

91. McDonough IM. Beta-amyloid and Cortical thickness reveal racial disparities in preclinical Alzheimer's disease. Neuroimage: Clinical. 2017;16:659-67. https://doi.org/10.1016/j.nicl.2017.09.014.

92. Reitan RM. The relation of the trail making test to organic brain damage. J Consult Psychol. 1955;19(5):393-4. https://doi.org/10.1037/h0044509.

93. Salthouse TA. What do adult age differences in the digit symbol substitution test reflect? J Gerontol. 1992;47(3):P121-8. https://doi.org/10.1 093/geronj/47.3.P121.

94. Wechsler D. Wechsler adult intelligence scale-Fourth Edition (WAIS-IV). San Antonio, TX: NCS Pearson. 2008;22(498):1.

95. Curra A, Pierelli F, Gasbarrone R, Mannarelli D, Nofroni I, Matone V, et al. The ventricular system enlarges abnormally in the seventies, earlier in men, and first in the frontal horn: a study based on more than 3,000 scans. Front Aging Neurosci. 2019;11:294. https://doi.org/10.3389/fnagi.2019.00294.

96. Salat DH, Buckner RL, Snyder AZ, Greve DN, Desikan RS, Busa E, et al. Thinning of the cerebral cortex in aging. Cereb Cortex. 2004;14(7):721-30. https://doi.org/10.1093/cercor/bhh032.

97. Steen RG, Mull C, McClure R, Hamer RM, Lieberman JA. Brain volume in firstepisode schizophrenia: systematic review and meta-analysis of magnetic resonance imaging studies. Br J Psychiatry. 2006;188(6):510-8. https://doi. org/10.1192/bjp.188.6.510.

98. van Haren NE, Schnack HG, Cahn W, van den Heuvel MP, Lepage C, Collins $\mathrm{L}$, et al. Changes in cortical thickness during the course of illness in schizophrenia. Arch Gen Psychiatry. 2011;68(9):871-80. https://doi.org/10.1 001/archgenpsychiatry.2011.88.

99. Frisoni GB, Testa C, Zorzan A, Sabattoli F, Beltramello A, Soininen H, et al. Detection of grey matter loss in mild Alzheimer's disease with voxel based morphometry. J Neurol Neurosurg Psychiatry. 2002;73(6):657-64. https://doi. org/10.1136/jnnp.73.6.657.

100. Jones DT, Machulda MM, Vemuri P, McDade E, Zeng G, Senjem M, et al. Age-related changes in the default mode network are more advanced in Alzheimer disease. Neurology. 2011;77(16):1524-31. https://doi.org/10.1212/ WNL.0b013e318233b33d.

101. Cao K, Chen-Plotkin AS, Plotkin JB, Wang LS. Age-correlated gene expression in normal and neurodegenerative human brain tissues. PLOS ONE. 2010;5(9):e13098.

102. Anderson VM, Schott JM, Bartlett JW, Leung KK, Miller DH, Fox NC. Gray matter atrophy rate as a marker of disease progression in AD. Neurobiol Aging. 2012;33(7):1194-202. https://doi.org/10.1016/j.neurobiolaging.2010.11.001.

103. Ashburner J, Csernansky JG, Davatzikos C, Fox NC, Frisoni GB, Thompson PM. Computer-assisted imaging to assess brain structure in healthy and diseased brains. Lancet Neurol. 2003;2(2):79-88. https://doi.org/10.1016/S14 74-4422(03)00304-1.

104. Driscoll I, Davatzikos C, An Y, Wu X, Shen D, Kraut M, et al. Longitudinal pattern of regional brain volume change differentiates normal aging from MCl. Neurology. 2009;72(22):1906-13. https://doi.org/10.1212/WNL.0b013e31 $81 \mathrm{a} 82634$

105. Malpetti M, Ballarini T, Presotto L, Garibotto V , Tettamanti M, Perani D, et al. Gender differences in healthy aging and Alzheimer's dementia: a (18) FFDG-PET study of brain and cognitive reserve. Hum Brain Mapp. 2017;38(8): 4212-27. https://doi.org/10.1002/hbm.23659.

106. Takahashi R, Ishii K, Kakigi T, Yokoyama K. Gender and age differences in normal adult human brain: voxel-based morphometric study. Hum Brain Mapp. 2011;32(7):1050-8. https://doi.org/10.1002/hbm.21088.

107. Wang Y, Xu Q, Luo J, Hu M, Zuo C. Effects of age and sex on subcortical volumes. Front Aging Neurosci. 2019;11:259. https://doi.org/10.3389/fnagi.2 019.00259 .

108. Xu J, Kobayashi S, Yamaguchi S, lijima K, Okada K, Yamashita K. Gender effects on age-related changes in brain structure. AJNR Am J Neuroradiol. 2000;21(1):112-8.

109. Good CD, Johnsrude IS, Ashburner J, Henson RN, Friston KJ, Frackowiak RS A voxel-based morphometric study of ageing in 465 normal adult human brains. Neuroimage. 2001;14(1 Pt 1):21-36. https://doi.org/10.1006/nimg.2 001.0786 .

110. Jack CR Jr, Wiste HJ, Weigand SD, Knopman DS, Vemuri P, Mielke MM, et al. Age, sex, and APOE epsilon4 effects on memory, brain structure, and betaamyloid across the adult life span. JAMA Neurol. 2015;72(5):511-9. https:// doi.org/10.1001/jamaneurol.2014.4821.

111. Zhang X, Liang M, Qin W, Wan B, Yu C, Ming D. Gender differences are encoded differently in the structure and function of the human brain 
revealed by multimodal MRI. Front Hum Neurosci. 2020;14:244. https://doi. org/10.3389/fnhum.2020.00244.

112. Bora E, Akdede BB, Alptekin K. The relationship between cognitive impairment in schizophrenia and metabolic syndrome: a systematic review and meta-analysis. Psychol Med. 2017;47(6):1030-40. https://doi.org/10.1017/ S0033291716003366.

113. Gustafson D, Lissner L, Bengtsson C, Bjorkelund C, Skoog I. A 24-year followup of body mass index and cerebral atrophy. Neurology. 2004;63(10):187681. https://doi.org/10.1212/01.WNL.0000141850.47773.5F.

114. Jagust W, Harvey D, Mungas D, Haan M. Central obesity and the aging brain. Arch Neurol. 2005;62(10):1545-8. https://doi.org/10.1001/archneur.62.1 0.1545 .

115. Luckhoff HK, du Plessis S, Scheffler F, Phahladira L, Kilian S, Buckle C, et al. Fronto-limbic white matter fractional anisotropy and body mass index in first-episode schizophrenia spectrum disorder patients compared to healthy controls. Psychiatry Res Neuroimaging. 2020;305:111173. https://doi.org/10.1 016/.jpscychresns.2020.111173.

116. Raji CA, Ho AJ, Parikshak NN, Becker JT, Lopez OL, Kuller LH, et al. Brain structure and obesity. Hum Brain Mapp. 2010;31(3):353-64. https://doi.org/1 $0.1002 / \mathrm{hbm} .20870$

117. O'Brien PD, Hinder LM, Callaghan BC, Feldman EL. Neurological consequences of obesity. Lancet Neurol. 2017;16(6):465-77. https://doi.org/1 0.1016/S1474-4422(17)30084-4.

118. Colcombe SJ, Erickson Kl, Raz N, Webb AG, Cohen NJ, McAuley E, et al. Aerobic fitness reduces brain tissue loss in aging humans. J Gerontol A Biol Sci Med Sci. 2003:58(2):176-80.

119. Colcombe SJ, Kramer AF, Erickson KI, Scalf P, McAuley E, Cohen NJ, et al. Cardiovascular fitness, cortical plasticity, and aging. Proc Natl Acad Sci U S A. 2004;101 (9):3316-21. https://doi.org/10.1073/pnas.0400266101.

120. Erickson KI, Leckie RL, Weinstein AM. Physical activity, fitness, and gray matter volume. Neurobiol Aging. 2014;35(Suppl 2):S20-8. https://doi.org/1 0.1016/j.neurobiolaging.2014.03.034.

121. Okonkwo OC, Schultz SA, Oh JM, Larson J, Edwards D, Cook D, et al. Physical activity attenuates age-related biomarker alterations in preclinical AD. Neurology. 2014;83(19):1753-60. https://doi.org/10.1212/WNL. 0000000000000964 .

122. Mukamal K, Longstreth WT Jr, Mittleman MA, Crum RM, Siscovick DS. Alcohol consumption and subclinical findings on magnetic resonance imaging of the brain in older adults: the cardiovascular health study. Stroke. 2001;32(9):1939-46. https://doi.org/10.1161/hs0901.095723.

123. Zhou S, Xiao D, Peng P, Wang SK, Liu Z, Qin HY, et al. Effect of smoking on resting-state functional connectivity in smokers: An fMRI study. Respirology. 2017;22(6):1118-24. https://doi.org/10.1111/resp.13048.

124. Cole JH, Franke K. Predicting age using neuroimaging: innovative brain ageing biomarkers. Trends Neurosci. 2017;40(12):681-90. https://doi.org/10.1 016/j.tins.2017.10.001.

125. Uludag K, Roebroeck A. General overview on the merits of multimodal neuroimaging data fusion. Neuroimage. 2014;102(Pt 1):3-10. https://doi. org/10.1016/j.neuroimage.2014.05.018.

126. Cole JH, Poudel RPK, Tsagkrasoulis D, Caan MWA, Steves C, Spector TD, et al. Predicting brain age with deep learning from raw imaging data results in a reliable and heritable biomarker. Neuroimage. 2017;163:115-24. https:// doi.org/10.1016/j.neuroimage.2017.07.059.

127. LeCun Y, Bengio Y, Hinton G. Deep learning. Nature. 2015;521(7553):436-44. https://doi.org/10.1038/nature14539.

128. Plis SM, Hjelm DR, Salakhutdinov R, Allen EA, Bockholt HJ, Long JD, et al. Deep learning for neuroimaging: a validation study. Front Neurosci. 2014;8: 229.

129. Zhang YD, Dong Z, Wang SH, Yu X, Yao X, Zhou Q, et al. Advances in multimodal data fusion in neuroimaging: overview, challenges, and novel orientation. Inf Fusion. 2020;64:149-87. https://doi.org/10.1016/j.inffus.2020. 07.006.

130. Johnson TE. Recent results: biomarkers of aging. Exp Gerontol. 2006;41(12): 1243-6. https://doi.org/10.1016/j.exger.2006.09.006.

\section{Publisher's Note}

Springer Nature remains neutral with regard to jurisdictional claims in published maps and institutional affiliations.

Ready to submit your research? Choose BMC and benefit from:

- fast, convenient online submission

- thorough peer review by experienced researchers in your field

- rapid publication on acceptance

- support for research data, including large and complex data types

- gold Open Access which fosters wider collaboration and increased citations

- maximum visibility for your research: over $100 \mathrm{M}$ website views per year

At $\mathrm{BMC}$, research is always in progress.

Learn more biomedcentral.com/submissions 